\title{
Mitochondrial Ceramide in Stroke
}

\author{
Tatyana I. Gudz and Sergei A. Novgorodov \\ Ralph H. Johnson Veterans Affairs Medical Center and the Departments of Neuroscience \\ and Medicine of Medical University of South Carolina, Charleston, South Carolina, \\ USA
}

\section{Introduction}

Sphingolipids are essential structural components of cellular membranes, playing prominent roles in signal transduction that governs cell proliferation, differentiation, migration, and apoptosis. Most sphingolipids are ubiquitous, but complex sphingolipids, including sphingomyelin (SM) and glycosphingolipids (GSLs), are more abundant in the brain and are particularly abundant in myelin. Sphingolipids are defined by the presence of a long-chain sphingoid backbone, generally sphingosine. Acylation of the sphingoid base, i.e. addition of a $\mathrm{C}_{14}-\mathrm{C}_{26}$ fatty acid to the amino group, yields ceramide, a building block for more complex sphingolipids. Neural cells are particularly enriched in GSLs and SM which is also a major lipid component of myelin. Sphingolipids are abundant in the plasma membranes and have unique molecular structures and conformational properties that cause them to form segregated compositional lipid domains in phospholipid bilayers (Sonnino et al., 2006). Membrane lipid domains, zones of the membrane with reduced fluidity, contain complex lipids of the cell, but are highly enriched in cholesterol and sphingolipids. Importantly, the proteins involved in signal transduction appear to segregate also in the lipid domains where they can exert their functions. Experimental evidence indicating that sphingolipids function through membrane reorganization and formation of lipid domains is summarized in a recent review by Kolesnick and Stancevic (Stancevic and Kolesnick, 2010). In addition to their role as building blocks of cellular membranes, sphingolipids have been reported to be pleotropic modulators of numerous enzymes in intracellular signaling pathways. Basic organization and specific principles of sphingolipid-mediated cell regulation have been reviewed by Hannun and Obeid (Hannun and Obeid, 2008, 2011).

After more than a decade of extensive investigations, it has become clear that ceramide is a key sphingolipid messenger regulating a diverse range of cell-stress responses, including apoptosis, cell senescence, and autophagy. Ceramide is tightly regulated in cells, and its participation in cell death signaling pathways is controlled by rapid conversion of ceramide into less deleterious sphingolipids (Scheme 1). Thus, ceramide can be metabolized into complex sphingolipids by glucosylceramide synthase or into SM by SM synthase, or into ceramide-1-phosphate by ceramide kinase (Hannun and Obeid, 2002; Ogretmen and Hannun, 2004), or into sphingosine-1-phosphate by ceramidase and sphingosine kinase (Hannun and Obeid, 2008). However, pathological conditions, including cerebral ischemia/reperfusion, could disturb ceramide metabolism resulting in ceramide accumulation that ultimately leads to cell death. 


\section{Pathways of ceramide generation}

Ceramide is a family comprised of about 50 distinct molecular species characterized by various acyl chains, their desaturation, and hydroxylation. Ceramide is an Nacylsphingosine consisting of a fatty acid bound to the amino group of the sphingoid base, sphingosine. Ceramides can contain monounsaturated or saturated fatty acids of various lengths from 2 to 28 carbon atoms, and the fatty acid chain length profoundly alters ceramide's biophysical properties. Short-chain ceramides with fatty acyl chains of fewer than 12 carbons can be easily dispersed in water and serve as detergents (Sot et al., 2005b). In contrast, most ceramides found in mammalian cellular membranes contain long fatty acyl chains of 16-28 carbon atoms rendering them hydrophobic lipids lacking detergent properties. Short-chain ceramides mix much better with phospholipids, promote a positive curvature in lipid monolayers, and their capacities to increase bilayer permeability or transbilayer motion are very low or non-existent. In situ enzymatic generation, or external addition, of long-chain ceramides in membranes has at least three important effects: (i) the lipid monolayer has an increased tendency to adopt a negative curvature, e.g. through a transition to an inverted hexagonal structure (Graham and Kozlov, 2010), (ii) the bilayer permeability to aqueous solutes is notoriously enhanced, and (iii) a transbilayer (flip-flop) lipid motion is promoted (Goni et al., 2005).

As a result, ceramide metabolism is restricted to cellular membranes and is highly compartmentalized. Hydrophobic ceramides are generated by membrane-associated enzymes, and exert their effects either in close proximity to the generation site or require specific transport mechanisms to reach their targets in another intracellular compartment (Futerman and Riezman, 2005). Long-chain ceramides appear to be able to flip-flop across the membrane (Lopez-Montero et al., 2005); however, spontaneous inter-bilayer transfer is extremely slow (Contreras et al., 2010). Therefore, the transfer of ceramide between intracellular compartments is facilitated by vesicular transport pathways (Perry and Ridgway, 2005). Alternatively, ceramide is transported by a non-vesicular pathway involving a transfer protein, CERT, from its generation site in the endoplasmic reticulum (ER) to the Golgi where it is required for SM synthesis (Hanada et al., 2003). In addition to de novo biosynthesis, ceramide is generated by sphingomyelinases (SMases) from SM in two major pathways: the neutral SMase (nSMase)-dependent pathway and aSMase (aSMase)dependent pathway or salvage (recycling) pathway (Scheme 1).

\subsection{De novo ceramide biosynthesis}

Remarkable progress has been made toward identifying enzymes involved in ceramide biosynthesis (Futerman and Riezman, 2005). (Dihydro) ceramide synthase (EC 2.3.1.24) is a key enzyme in de novo ceramide synthasis, and it utilizes fatty acid acyl CoA for $\mathrm{N}$-acylation of sphinganine (dihydrosphingosine) yielding dihydroceramide that is converted to ceramide by desaturase (Scheme 1). In yeast, longevity assurance gene 1 (LAG1) was identified as a component of ceramide synthase. Deletion of LAG1 in haploid cells resulted in a pronounced increase ( $50 \%)$ in mean and maximum life spans (D'Mello $\mathrm{N}$ et al., 1994). Mammalian homologs of LAG1, which belong to the LASS (longevity assurance gene homolog) family, were cloned and characterized (Futerman and Riezman, 2005). Each of the 6 known LASS (also known as CerS) genes appears to regulate synthesis of a specific subset of ceramides, and displays a unique substrate specificity profile for chain-length and/or saturation in fatty acid acyl CoA. Over-expression of any CerS protein in mammalian cells 


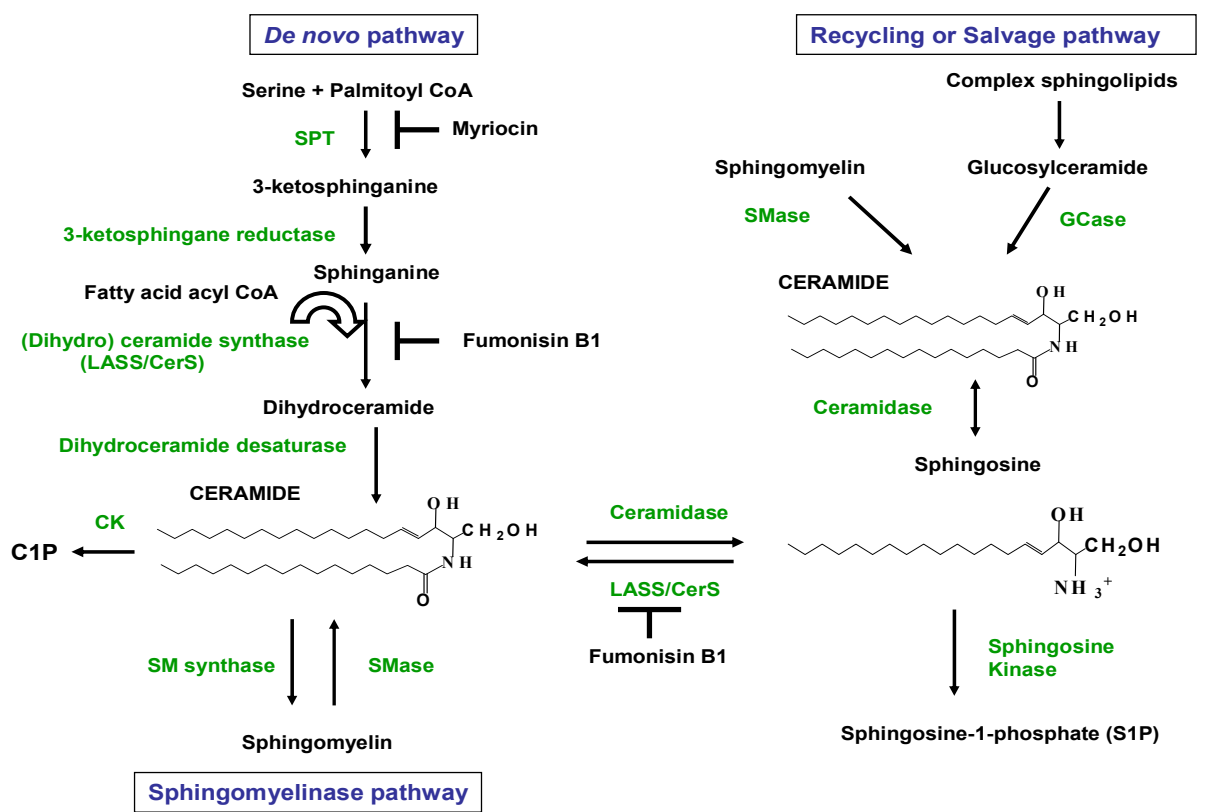

Scheme 1. Biosynthesis of ceramide and its conversion into other bioactive sphingolipids. De novo ceramide synthesis begins with the conversion of serine and fatty acyl CoA into 3ketosphinganine by serine palmitoyl transferase (SPT), then 3-ketosphinganine is converted into dihydrosphingosine. Myriocin is a potent inhibitor of SPT activity. (Dihydro) ceramide synthase (LASS/CerS) acylates dihydrosphingosine to form dihydroceramide, which is then reduced to ceramide by dihydroceramide desaturase. Ceramide is also produced by SMases through SM degradation in SMase pathway. Ceramidase converts ceramide into sphingosine, which is phosphorylated by sphingosine kinase (SK) to generate sphingosine1-phosphate. Ceramide is phosphorylated by ceramide kinase (CK) yielding ceramide-1phosphate (C1P). In the salvage or recycling pathway, complex sphingolipids are broken down to ceramide by glucosylceramidase (GCase) and then by ceramidase to sphingosine, which is re-acylated to ceramide by LASS/CerS. Fumonisin B1 inhibits LASS/CerS activity.

resulted in increased levels of a specific subset of ceramide species. It has been demonstrated that CerS1 exhibits high specificity for $\mathrm{C}_{18: 0}-\mathrm{CoA}$ generating $\mathrm{C}_{18: 0}$-ceramide (Mizutani et al., 2005). CerS2, CerS4, and CerS3 appear to have broader specificity (Laviad et al., 2008; Mizutani et al., 2006). CerS2 or CerS4 mainly synthesizes $C_{20: 0^{-}}, C_{22: 0^{-}}, C_{24: 1^{-}}, C_{24: 0^{-}}, C_{26: 1}$ and $C_{26: 0}$ ceramide,

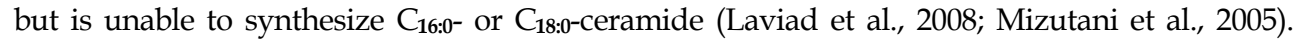
CerS3 generates $\mathrm{C}_{18: 0^{-}}, \mathrm{C}_{20: 0^{-}}, \mathrm{C}_{22: 0^{-}}$and $\mathrm{C}_{24: 0^{-}}$-ceramide (Mizutani et al., 2006). It has been shown that CerS5 generates $C_{14: 0^{-}}, C_{16: 0^{-}}, C_{18: 0^{-}}$, and $C_{18: 1^{-}}$ceramide (Lahiri and Futerman, 2005; Mizutani et al., 2005); and CerS6 produces $\mathrm{C}_{14: 0^{-}}, \mathrm{C}_{16: 0^{-}}$, and $\mathrm{C}_{18: 0^{-}}$-ceramide (Mizutani et al., 2005).

The availability of certain fatty acyl-CoA species and the characteristic distribution pattern of CerS family members in tissues seem to regulate the tissue-specificity of the ceramide species. Northern blot and real-time RT-PCR analysis revealed broad expression of CerS5, CerS4, and CerS6 genes in mammalian tissues, but CerS1 expression was limited to the brain and skeletal muscle (Laviad et al., 2008; Mizutani et al., 2006). Interestingly, CerS2 mRNA 
was more abundant than other CerS family members and had the broadest tissue distribution (Laviad et al., 2008). Except for a weak display in skin, CerS3 mRNA expression is limited almost solely to testis, implying that CerS3 plays an important role in this gland (Mizutani et al., 2006).

CerS are integral membrane proteins, but the exact number of transmembrane domains and their topology has not been resolved experimentally. All of the CerS genes have a highly conserved stretch of 52 amino acids known as the Lag1p motif which is essential for enzyme activity (Spassieva et al., 2006). Some of the CerS proteins are post-translationally modified, and, for instance, CerS6 is expressed as a native and an N-glycosylated form. The Nglycosylation site is conserved in CerS6, CerS2, and CerS5, but this post-translational modification is not required for ceramide synthase activity (Mizutani et al., 2005). Intriguingly, CerS1 phosphorylation appears to regulate the protein turnover (Sridevi et al., 2009). All CerS except CerS1 contain a homeobox domain, suggesting involvement in developmental regulation (Venkataraman and Futerman, 2002). De novo synthesis of ceramide is required for cell survival in vivo, and is widespread among cell types and tissues. Regulation of ceramide synthesis is only beginning to be understood. Regulation at the transcriptional level has been observed with a number of agents, including endotoxin and cytokines, UVB irradiation, and retinoic acid (Merrill, 2002).

De novo ceramide biosynthesis occurs in the endoplasmic reticulum (ER) where all the participating enzymes have been found (Hirschberg et al., 1993; Mandon et al., 1992; Michel and van Echten-Deckert, 1997). Ceramide is synthesized at the cytosolic side of the ER (Mandon et al., 1992; Merrill, 2002), serving as a precursor for the biosynthesis of glycosphingolipids and SM in the Golgi (Futerman et al., 1990; Kolter et al., 2002).

\subsection{Sphingomyelin hydrolysis}

SM hydrolysis by one of several SMases is another source of cellular ceramide. Three groups of SMases, acid, neutral, and alkaline, are distinguished by their primary structure, catalytic $\mathrm{pH}$ optimum, and localization.

\subsubsection{Acid SMase}

A well-characterized enzyme, acid SMase (aSMase) contributes to the catabolism of SM and ceramide formation in lysosomes (Tani et al., 2005; Tani et al., 2007). aSMase could relocate from intracellular compartments to the plasma membrane where it plays an important role in SM hydrolysis and ceramide generation within lipid rafts (Bollinger et al., 2005). aSMase is a soluble enzyme with no transmembrane domains, and the mechanism of aSMase association with the membrane, at which its substrate, SM, resides, remains unclear. aSMase is also secreted through the Golgi secretory pathway, and it is constitutively present in plasma (Spence et al., 1989) where it is involved in hydrolysis of lipoprotein-bound SM, the second most abundant lipid in human plasma. Intriguingly, aSMase hydrolyzes SM bound to oxidized LDL more effectively than SM bound to intact LDL (Schissel et al., 1998). The accelerated hydrolysis of SM could enhance LDL aggregation leading to macrophage foam cell formation, suggesting a role for secretory aSMase in the pathogenesis of arteriosclerosis (Tabas, 1999).

\subsubsection{Neutral SMase}

Three mammalian closely related isoforms of neutral SMase (nSMase) have been recently cloned, including nSMase1, nSMase2 and mitochondria-associated nSMase (MA-nSMase) 
(Clarke et al., 2011). nSMase1 is localized to the ER and nucleus (Tomiuk et al., 2000). nSMase2 had a dynamic intracellular localization (Clarke et al., 2006), having been found in the Golgi of sub-confluent cells, at the plasma membrane at the regions of cell-cell contact (Marchesini et al., 2004) and in recycling compartments (Milhas et al., 2010). Furthermore, it appears that oxidative stress could induce nSMase 2 trafficking to the plasma membrane, whereas antioxidant (glutathione) directed its translocation to the perinuclear region (Levy et al., 2006). MA-nSMase is found within the mitochondria and associated membranes $(\mathrm{Wu}$ et al., 2010). The physiological role of neutral SMase isoforms may be dictated by their immediate environment in the specific intracellular compartment. Alkaline SMase lacks homology to neutral or aSMase and its mRNA is abundant in the intestine where the enzyme plays a major role in digestion of dietary SM (Nilsson and Duan, 2006).

\subsection{Recycling or salvage pathway}

Ceramide is also produced during the recycling of sphingosine in the process termed the "salvage pathway" (Kitatani et al., 2008). In this process, complex sphingolipids are broken down to ceramide and then to sphingosine, which is then used by ceramide synthase to yield ceramide. SM is converted to ceramide by aSMase. Ceramide accumulation via the salvage pathway requires ceramide synthase which is important in de novo synthesis of ceramide. Complex sphingolipids undergo constitutive degradation in the late endosomes and the lysosomes yielding ceramide which does not leave the lysosomes (Chatelut et al., 1998) unless converted into sphingosine by acid ceramidase. Free sphingosine could be released from the lysosomes and re-acylated by ceramide synthase to form ceramide.

\section{Ceramide generation in mitochondria}

Mitochondria arise as important intracellular compartment for ceramide metabolism, and they have been shown to contain a variety of sphingolipids, including SM and ceramide (Ardail et al., 2001; Tserng and Griffin, 2003). Mounting evidence suggests a local action of ceramide on mitochondria in intact cells. Thus, selective hydrolysis of a mitochondrial pool of SM by overexpressed sphingomyelinase (bSMase) targeted to mitochondria resulted in apoptosis. In contrast, generation of ceramide in the plasma membrane, ER, or Golgi apparatus by bSMase targeted to these compartments had no effect on cell viability (Birbes et al., 2001). Recently, mitochondrial ceramide engagement in apoptosis has been shown using loss-of-function mutants of ceramide synthase in the germ cell line of C. elegans (Deng et al., 2008). In this study, an ionizing radiation-induced apoptosis of germ cells was obliterated upon inactivation of ceramide synthase, and restored upon microinjection of long-chain ceramide. Radiation-induced increase in ceramide localized to mitochondria was required for activation of CED-3 caspase and apoptosis. These studies underscore the physiological significance of the mitochondrial ceramide and SM pools (Andreyev et al., 2010; Ardail et al., 2001; Dai et al., 2004; Monette et al., 2010; Tserng and Griffin, 2003; Yabu et al., 2009).

Although several enzyme activities involved in ceramide metabolism have been demonstrated in mitochondria, the nature of enzymes generating ceramide in this organelle is still a matter of debate (Laviad et al., 2008). Mitochondria evolve as a specialized compartment of sphingolipid metabolism with their own subset of ceramide synthesizing and degrading enzymes. Three possibilities may account for ceramide generation in mitochondria. 
First, experimental evidence suggests the presence of ceramide synthase activity in mitochondria. Thus, ceramide synthase activity was first detected (Morell and Radin, 1970; Ullman and Radin, 1972) and partially purified from a bovine brain mitochondria-enriched fraction (Shimeno et al., 1995) which was not characterized in terms of marker enzyme activities. Mitochondrial enzymes had almost 2-fold higher specific ceramide synthase activity than the ceramide synthase from the ER. The mitochondrial enzyme had a $\mathrm{pH}$ optimum around 7.5 and maximal catalytic efficiency with $\mathrm{C}_{16: 0^{-}}$or $\mathrm{C}_{18: 0-a c y l} \mathrm{CoA}$. The addition of liposomes to the mitochondrial enzyme increased ceramide synthase activity (approx. 7.8-fold) (Shimeno et al., 1995). Purification of ceramide synthase from bovine liver mitochondria yielded two major protein bands, 62 and $72 \mathrm{kDa}$ on a SDS-gel (Shimeno et al., 1998). This enzyme had an apparent $\mathrm{Km}$ of $146 \mu \mathrm{M}$ and $V \max$ of $11.1 \mathrm{nmol} / \mathrm{min} / \mathrm{mg}$ protein with $\mathrm{C}_{18: 0-a c y l} \mathrm{CoA}$, and corresponding values of $\operatorname{Vmax} 144 \mu \mathrm{M}$ and $8.5 \mathrm{nmol} / \mathrm{min} / \mathrm{mg}$ protein towards sphinganine.

Detailed analysis of ceramide synthase activity in highly purified mitochondria by Bionda et al. essentially confirmed previous findings (Bionda et al., 2004). Ceramide synthase activity was demonstrated in rat liver mitochondria and in the sub-compartment of the ER closely associated with mitochondria. Further sub-mitochondrial investigation of ceramide synthase activity revealed that both outer and inner mitochondrial membranes can synthesize ceramide (Bionda et al., 2004). Recent reports describing several ceramide synthase isoforms, including CerS1, CerS2, CerS4 and CerS6, in purified mouse brain mitochondria (Novgorodov et al., 2011a; Yu et al., 2007) support the notion that several ceramide synthesizing enzymes could be localized in mitochondria (Futerman, 2006). No such association was found in HeLa cells (Mesicek et al., 2010), suggesting that this might be a cell type/tissue specific event. The intramitochondrial localization of CerS was examined in purified brain mitochondria by immunoprecipitation (Novgorodov et al., 2011a). These studies reveal a selective CerS6 association with adenine nucleotide translocase, the inner membrane component of the mitochondrial permeability transition pore (MPTP). In contrast, CerS2 associated with the outer membrane resident protein Tom20, a receptor of the protein import complex. The data suggest CerS6/ceramide could regulate MPTP activity and mitochondrial $\mathrm{Ca}^{2+}$ homeostasis whereas CerS2/ceramide could modulate the mitochondrial protein import machinery.

Secondly, recent studies identified two novel SMases, which hydrolyze SM to ceramide, and phosphocholine in mitochondria from zebrafish (Yabu et al., 2009) and mouse tissues (Wu et al., 2010). Notably, in yeast, the mammalian nSMase ortholog Isc1p associates with mitochondria in the post-diauxic phase of yeast growth and regulates mitochondrial sphingolipid metabolism (Kitagaki et al., 2007; Vaena de Avalos et al., 2004).

Thirdly, the additional source of ceramide in mitochondria is a reverse reaction of a neutral ceramidase (nCDase), e.g., formation of ceramide as a result of condensation of palmitate and sphingosine (El Bawab et al., 2001). On the basis of molecular cloning and confocal microscopy data, this activity was ascribed to mitochondria (El Bawab et al., 2000), and it was demonstrated in purified mitochondria (Bionda et al., 2004). Recent studies describe the molecular mechanism of ceramide generation from palmitate and sphingosine in purified liver mitochondria that requires concerted action of two enzymes nCDase and thioesterase (which hydrolyzes palmitoyl-CoA to CoA and fatty acid)(Novgorodov et al., 2011b). Thus, mitochondria from nCDase-deficient mice have significantly decreased formation of ceramide from sphingosine and palmitoyl-CoA (or palmitate) compared to mitochondria from wild type mice, indicating that nCDase participates in ceramide formation in liver 
mitochondria, and that ceramide formation may occur from sphingosine and palmitoyl-CoA from coupled activities of a mitochondrial thioesterase and nCDase catalyzing the reverse reaction (Scheme 2). Another possibility is that ceramide could be also transported from the ER to mitochondria through the contact sites between them (Stiban et al., 2008).

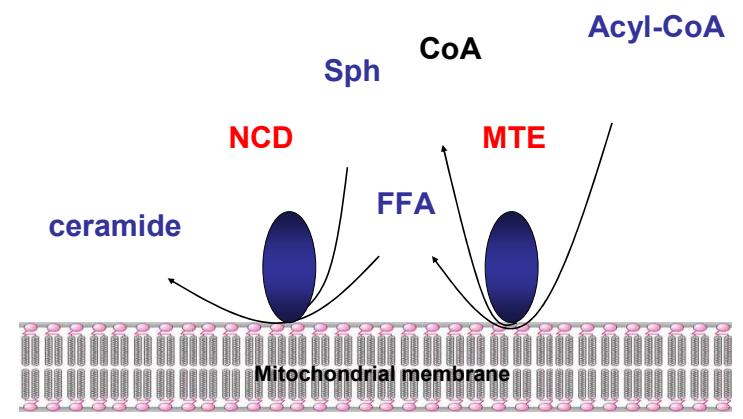

Scheme 2. Ceramide formation from Acyl-CoA and sphingosine (Sph) mediated by coupled activities of mitochondrial thioesterase (MTE) and nCDase (NCD).

\section{Ceramide accumulation in Ischemia/Reperfusion (IR)}

Ceramide accumulation has been demonstrated in various in vivo models of IR and it has been implicated as an important mediator of apoptosis in the injured tissue, but mechanisms of ceramide generation are not well-defined and the downstream targets of ceramide remain unresolved. The IR-induced accumulation of ceramide appears to be a general phenomenon for heart, kidney, liver and brain. The identification and characterization of key proteins of ceramide synthesis are expected to expand our understanding of molecular mechanisms behind ceramide's involvement in IR-induced tissue damage.

Research progress has been hampered by a lack of appropriate techniques that would allow simultaneous analysis of multiple sphingolipid species. Thus, the most common method for quantification of ceramide, the diglyceride (DG) kinase assay (Bielawska et al., 2001) has significant disadvantages including a limited separation of ceramide from dihydroceramide and the inability to determine the individual molecular species of ceramide. Recent advances in the development of new mass spectroscopy-based methods for quantitative analysis of sphingolipid molecular species may allow further dissection of ceramide specific pathways (Pettus et al., 2004; Sullards, 2000).

Increasing evidence suggests that the fatty acid chain of ceramide is an important determinant of the biological effect mediated by the individual ceramide species. Most of the experimental evidence indicating the important roles of ceramides containing distinct fatty acids is summarized in an excellent review by Futerman and his colleagues (PewznerJung et al., 2006), and new studies further support the notion of distinct roles of ceramide species in cell metabolism(Hannun and Obeid, 2011). It has been demonstrated that generation of $\mathrm{C}_{18: 0}$-ceramide, and not $\mathrm{C}_{16: 0}$-ceramide repressed human telomerase reverse transcriptase promoter in lung carcinoma cells (Wooten-Blanks et al., 2007). Activation of aSMase in the salvage pathway brought about a selective accumulation of $\mathrm{C}_{16: 0}$-ceramide (Chudakova et al., 2008; Kitatani et al., 2006) due to the involvement of ceramide synthase CerS5 localized in mitochondria-associated membranes (Kitatani et al., 2006). In another 
study, the effects of chronic hypoxia on selected ceramide species were examined in cardiac tissue in a neonatal mouse model (Noureddine et al., 2008). The study revealed the differential involvement of the right ventricle with regard to levels of $C_{16: 0}$-ceramide and its precursor, dihydro- $\mathrm{C}_{16: 0}$-ceramide. The decrease in $\mathrm{C}_{16: 0}$-ceramide observed in both hypoxic and control right ventricles over time occurred along with a significant increase in dihydro$\mathrm{C}_{16: 0}$-ceramide in hypoxic but not control tissues suggesting a role for dihydro- $\mathrm{C}_{16: 0^{-}}$ ceramide in the adaptive tissue response to hypoxia. Although ceramide species could have different effects on biophysical properties of the membrane lipid bilayer (Sot et al., 2005a), it remains unclear how ceramides containing different fatty acids exert their effects upon cell physiology.

\subsection{Cardiac ischemia}

In several studies, elevated ceramide has been reported in myocardium after ischemia and IR. In the rat heart left coronary artery occlusion model, ischemia with subsequent reperfusion, but not ischemia alone, induced apoptosis in myocardial cells indicated by DNA laddering and measurement of soluble chromatin degradation products (Bielawska et al., 1997). The content of ceramide in ischemic myocardium was elevated to $155 \%$ baseline levels after $30 \mathrm{~min}$ ischemia, and was further increased to $250 \%$ after $3 \mathrm{~h}$ reperfusion. In the rabbit heart left coronary artery occlusion model, ceramide content was increased during the first minute of ischemia, peaking at 5 min with mean ceramide $~ 127 \%$ of baseline. However, this peak was transient because ceramide content returned to near-baseline values as soon as $10 \mathrm{~min}$ into the sustained ischemia (Argaud et al., 2004). In another study with the rat heart left coronary artery occlusion model, ceramide content in reperfused myocardium was found to increase up to $50 \%$. This increase was not associated with enhanced neutral or aSMase activity, but rather with reduced activity of ceramidase, a ceramide-metabolizing enzyme (Scheme 1) (Zhang et al., 2001). In a global rat heart ischemia model, ceramide content was elevated about 2-fold after $30 \mathrm{~min}$ ischemia/30 min reperfusion which was attributed to SM hydrolysis. Thus, there was about 50\% less SM in reperfused myocardium after IR (Cordis et al., 1998). This finding was confirmed in recent studies by the same group who reported an increased accumulation of ceramide in ischemic myocardium after 30 min ischemia/2 h reperfusion (Cui et al., 2004; Der et al., 2006). An inhibitor of aSMase activity desipramine prevented ceramide accumulation and provided cardioprotection. Intriguingly, a significant amount of ceramide accumulated in the caveolin-1-rich membrane microdomains after IR was abolished by pre-treatment with desipramine (Der et al., 2006). The ceramide-caveolin-1 interaction is believed to occur within lipid raft microdomains in membranes leading to rafts stabilization (Xu et al., 2001) and alteration of receptor tyrosine kinase signal transduction (Zundel et al., 2000).

In a very interesting study, analysis of cardiac tissues from mice subjected to IR revealed significant elevation of ceramide and inhibition of sphingosine kinase 1 activity (Scheme 1) that could ultimately result in decreased sphingosine-1-phosphate (Pchejetski et al., 2007). Furthermore, sphingosine kinase 1 inhibition, ceramide accumulation, cardiomyocyte apoptosis, and infarct size were significantly decreased in mitochondrial monoamine oxidase (MAO-A)-deficient mice after IR. MAO-A appears to play an important role in reactive oxygen species (ROS)-dependent cardiomyocytes apoptosis and postischemic cardiac damage (Bianchi et al., 2005). The data imply that the upregulation of ceramide/sphingosine-1-phosphate ratio is a critical event in MAO-A-dependent cardiac cell apoptosis in IR. 
Recently, increases of specific ceramide species in the rat heart were investigated after 30 min global ischemia/30 min reperfusion. IR increased accumulation of only 7 out of 14 ceramide species identified in the heart (Beresewicz et al., 2002). Of note, the relative magnitude of IR-induced myocardial accumulation of ceramide species was not proportional to their basal tissue concentrations. For instance, although $\mathrm{C}_{16: 0 \text {-ceramide and }}$

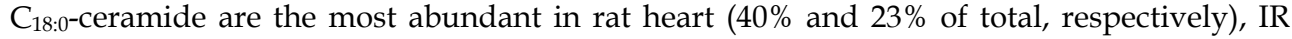

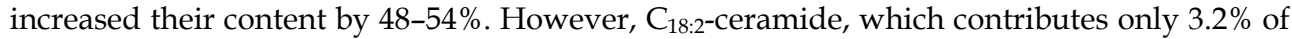
total myocardial ceramides, was increased by $281 \%$. These findings suggest the role of specific ceramide species signaling in the mechanism of post-ischemic myocardial injury.

In vitro, hypoxia/reoxygenation activated nSMase and ceramide accumulation in cardiomyocytes implicating the production of free radicals (Hernandez et al., 2000). nSMase activation could be abrogated by inhibition of a factor associated with nSMase activation (FAN) which is an adaptor protein connecting neutral SMase to the TNF receptor signaling pathway (O'Brien et al., 2003).

\subsection{Liver ischemia}

Ceramide was elevated in injured liver tissue after cold ischemia and warm reperfusion during liver transplantation (Bradham et al., 1997). A critical role of aSMase and ceramide accumulation was demonstrated in another study of hepatic IR injury (Llacuna et al., 2006). Hepatic ceramide transiently increased after the reperfusion phase due to activation of aSMase followed by acid ceramidase stimulation. Knocking down aSMase by in vivo administration of siRNA decreased ceramide generation during IR, and attenuated hepatocellular necrosis, cytochrome c release, and caspase-3 activation. The study draws attention to an important role of ceramide in IR-induced liver damage and suggests that modulation of aSMase could be of therapeutic relevance in liver transplantation.

\subsection{Kidney ischemia}

In the whole kidney IR model, ceramide content was increased about 1.8-fold in the injured tissue during the reperfusion phase (Zager et al., 1997) which was not accompanied by SM hydrolysis. In fact, there was no SM content change in post-IR tissue. Analysis of SMase activity revealed that ischemia induced declines (50\%) in both acid and neutral SMase activity, and these persisted throughout the 24-h reperfusion period (Zager et al., 1998).

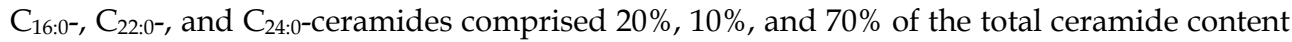
in kidney tissue, respectively (Kalhorn and Zager, 1999). IR dramatically increased $\mathrm{C}_{16: 0^{-}}$ ceramide (4-fold), and all other ceramides increased modestly. Interestingly, IR induced a striking shift towards unsaturated (vs. saturated) fatty acyl within $\mathrm{C}_{22: 0^{-}}$and $\mathrm{C}_{24: 0^{-}}$(but not $\left.\mathrm{C}_{16: 0^{-}}\right)$ceramide pools. The data imply that IR-induced inhibition of sphingomyelin hydrolysis results in accumulation of ceramide, the substrate in sphingomyelin synthetic pathway.

\subsection{Cerebral ischemia}

Ischemic stroke occurs when cerebral or precerebral arteries are occluded or significantly stenosed by emboli or by local atherosclerotic disease. Within minutes of interrupted blood flow, mitochondrial energy production is shut down due to lack of oxygen resulting in membrane depolarization and excessive release of neurotransmitters, specifically, glutamate. Extracellular glutamate accumulation over-stimulates glutamate receptors, 
promoting cytosolic $\mathrm{Ca}^{2+}$ overload, the generation of ROS, and mitochondrial dysfunction leading to cell death.

A few studies reported ceramide accumulation during cerebral ischemia and IR (Kubota et al., 1989; Nakane et al., 2000), and it appears that the mechanism of ceramide accumulation depends on the severity of the insult to the brain. Thus, severe and lethal cerebral IR resulted in ceramide accumulation via activation of aSMase and SM hydrolysis (Kubota et al., 1989; Kubota et al., 1996; Nakane et al., 2000) or inhibition of ceramide utilization by glucosylceramide synthase (Takahashi et al., 2004). Consistent with these data, the extent of brain tissue damage was decreased in mice lacking aSMase (Yu et al., 2000). In a recent study, severe cerebral IR induced SM hydrolysis and increased ceramide and sphingosine in the ischemic brain (Chudakova et al., 2008). Similarly, chronic cerebral ischemia caused ceramide accumulation due to activation of SM degradation accompanied by reduced ceramide utilization via glucosylceramide synthase (Ohtani et al., 2004). The data highlight IR-induced deregulation of complex sphingolipids metabolism.

In mild IR, ceramide accumulation resulted from de novo ceramide biosynthesis rather from hydrolysis of SM (Yu et al., 2007). There is apparent tissue specificity in the expression of individual ceramide species that might reflect the tissue specificity of the ceramide synthases. In brain, $\mathrm{C}_{18: 0^{-}}, \mathrm{C}_{18: 1^{-}}$and $\mathrm{C}_{24: 1^{-}}$-ceramide are the major species expressed $(39.5 \%$, $34 \%$, and $12.5 \%$ of total ceramide, respectively) whereas $C_{16: 0-}$ ceramide contributes only $4 \%$ of total ceramide. All ceramide species were elevated in the ischemic brain about 1.5-2-fold. The enhanced accumulation of sphingolipids seems to occur during the reperfusion phase; there were no changes in sphingolipid content after ischemia without reperfusion. This finding is in line with data which show that both ischemia and the restoration of blood flow to ischemic tissue (reperfusion) causes cellular damage by different molecular mechanisms (Chan, 2004; Gustafsson and Gottlieb, 2008).

Investigation of intracellular sites of ceramide accumulation after mild IR revealed the elevation of ceramide species both in purified mitochondria and in the ER (Yu et al., 2007). In mitochondria, only $\mathrm{C}_{18: 0^{-}}, \mathrm{C}_{18: 1^{-}}$and $\mathrm{C}_{16: 0^{-}}$-ceramides were increased, but all ceramide species increased in the ER suggesting activation of different ceramide synthases in these intracellular compartments. Indeed, several ceramide synthases were identified in mitochondria and the ER, including CerS1, CerS2, and CerS6, but CerS5 was localized only in the ER in the brain. Activity measurements indicated activation of CerS6 in ischemic mitochondria apparently via post-translational mechanisms; IR did not affect the CerS6 protein expression (Yu et al., 2007).

It appears that CerS6 is developmentally regulated and primarily generates $\mathrm{C}_{16: 0}$-ceramide in brain mitochondria (Novgorodov et al., 2011a). An investigation into the role of CerS6 in mitochondria revealed that ceramide synthase down-regulation during brain development is associated with dramatically decreased mitochondrial $\mathrm{Ca}^{2+}-$ loading capacity (CLC) which could be rescued by addition of ceramide. Ceramide-mediated blockade of MPTP opening seems to be the underlying mechanism of the increased CLC in brain mitochondria isolated from young animals. In fact, mitochondria maintain low cytosolic $\mathrm{Ca}^{2+}$ levels by sequestering $\mathrm{Ca}^{2+}$ inside the mitochondrial matrix complexed with phosphate. Energized mitochondria take up $\mathrm{Ca}^{2+}$ via the mitochondrial calcium uniporter which has been recently described as a highly selective, inwardly rectifying channel (Kirichok et al., 2004). Excessive accumulation of $\mathrm{Ca}^{2+}$ in the mitochondrial matrix could trigger opening of MPTP at a high conductance state, which would be accompanied by dissipation of the transmembrane potential and mitochondrial swelling. In brain mitochondria, $\mathrm{Ca}^{2+}$ may also activate a 
limited permeability state of MPTP opening (Novgorodov and Gudz, 1996) that only depolarizes mitochondria without causing swelling (Brustovetsky and Dubinsky, 2000b). This depolarization dramatically reduces the driving force for $\mathrm{Ca}^{2+}$ influx via mitochondrial $\mathrm{Ca}^{2+}$ uniporter, thus limiting the mitochondrial ability to sequester $\mathrm{Ca}^{2+}$ (Brustovetsky and

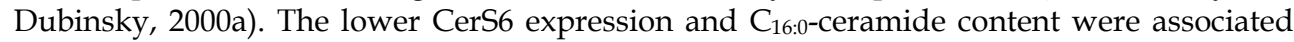
with reduced mitochondrial CLC in adult brain mitochondria, whereas exogenous $\mathrm{C}_{16: 0^{-}}$ ceramide restored CLC to that of young brain mitochondria. This is in line with the finding that long-chain ceramides, including $\mathrm{C}_{16: 0}$-ceramide, are potent inhibitors of MPTP activity (Novgorodov et al., 2008). This suggests that CerS6-generated ceramide could prevent MPTP opening, leading to increased $\mathrm{Ca}^{2+}$ accumulation in the mitochondrial matrix.

The role of CerS6 in cell survival was examined in primary oligodendrocyte (OL) precursor cells, which undergo apoptotic cell death during early postnatal brain development or following cerebral IR. Exposure of OLs to glutamate resulted in apoptosis that was prevented by inhibitors of de novo ceramide biosynthesis, myriocin and fumonisin B1. Knockdown of CerS6 with siRNA reduced glutamate-triggered OL apoptosis, whereas knockdown of CerS5 had no effect. Importantly, blocking mitochondrial $\mathrm{Ca}^{2+}$ uptake or decreasing $\mathrm{Ca}^{2+}$-dependent protease calpain activity with specific inhibitors prevented OL apoptosis. Finally, knocking down CerS6 decreased calpain activation. The data suggest a novel role for CerS6 in the regulation of both mitochondrial $\mathrm{Ca}^{2+}$ homeostasis and calpain, which could be important in cell death after cerebral IR (Scheme 3). These studies illuminate a novel determinant in cerebral IR, mitochondrial ceramide synthase CerS6 which could be an important future target for neuroprotection.

In vitro, de novo synthesized ceramide increased after brief exposure of cultured brain cells to hypoxia, oxygen/glucose deprivation, or TNF (Ginis et al., 1999; Liu et al., 2000). In neuronal precursor cells, hypoxia/reoxygenation triggered a robust elevation in $\mathrm{C}_{14: 0^{-}}$and $\mathrm{C}_{16: 0^{-}}$-ceramides, and a small increase in $\mathrm{C}_{18: 0^{-}}, \mathrm{C}_{18: 1^{-}}$and $\mathrm{C}_{20: 0^{-}}$-ceramides, and no increase in

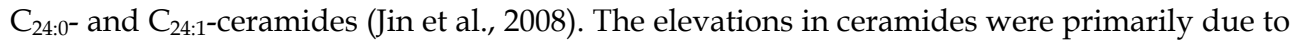
the actions of aSMase and ceramide synthase CerS5, demonstrating the involvement of the salvage pathway. Interestingly, $\mathrm{C}_{2}$-ceramide infusion protected the brain against IR injury (Chen et al., 2001; Furuya et al., 2001). However, this effect could be also attributed to the intracellular/extracellular conversion of ceramide into sphingosine-1-phosphate, which is known to protect cells from apoptosis (Hait et al., 2006; Taha et al., 2006; Tani et al., 2007).

\section{Ceramide and mitochondrial injury in stroke}

Although IR-induced mitochondrial injury has been extensively studied and mitochondrial functions affected by IR are characterized (Sims and Anderson, 2002), crucial information is needed regarding the cause of mitochondrial dysfunction. Our studies suggest that exogenously added ceramide could provoke mitochondrial dysfunctions similar to that occurring in cerebral IR (Yu et al., 2007). Of note, some data on mitochondrial effects of ceramide have been obtained using synthetic short-chain analogs, which may not fully mimic the properties of naturally occurring long-chain ceramides.

\subsection{Respiratory chain}

The restriction on mitochondrial respiratory chain function has been shown in various rodent models of stroke (Sims and Anderson, 2002). An impairment of Complex III has been 


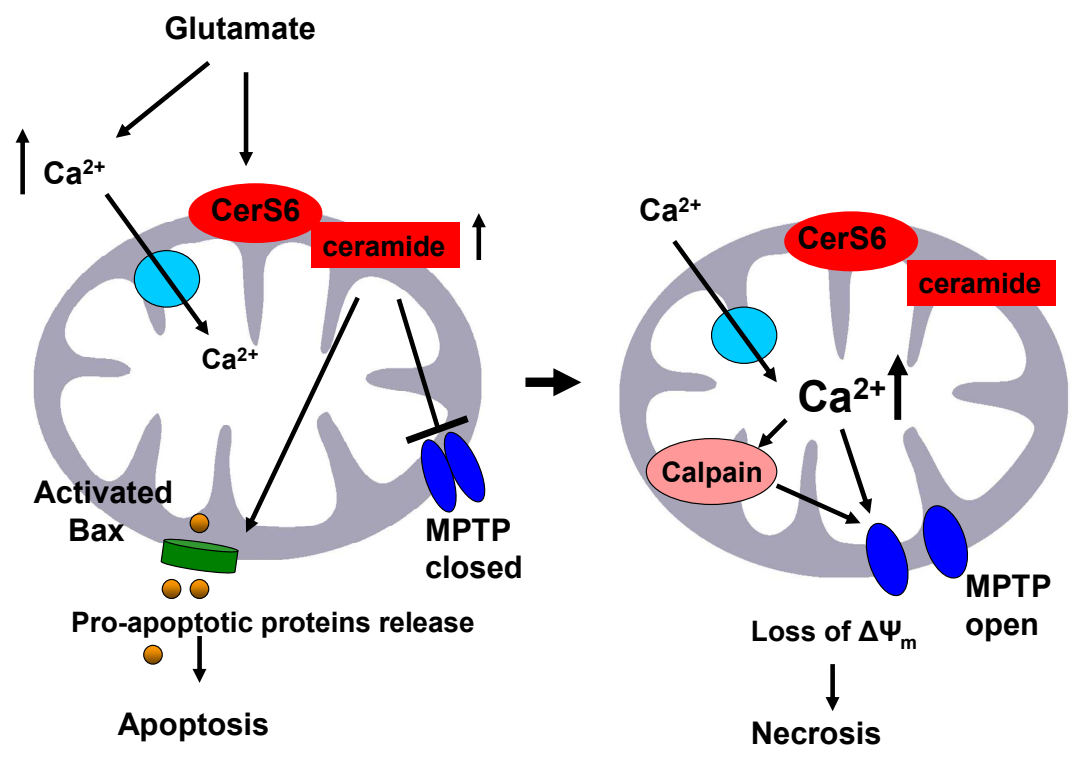

Scheme 3. Hypothetical role of CerS6/ceramide in mitochondria after cerebral IR. IR triggers glutamate-induced cytosolic $\mathrm{Ca}^{2+}$ influx into the mitochondria and an activation of mitochondrial CerS6 that elevates ceramide. Ceramide blocks the MPTP opening at a low conductance state, leading to increased $\mathrm{Ca}^{2+}$ in the mitochondrial matrix. This MPTP inactivation would allow mitochondria to support adequate ATP production for formation of the apoptosome, and might be responsible for the initial raise in ATP production (and hence $\Delta \psi$ ) during apoptosis (Atlante et al., 2005), an observation that corresponds well with the reported transient mitochondrial hyper-polarization in the apoptosis induced by IL-3 withdrawal (Vander Heiden et al., 1997). Rising mitochondrial $\mathrm{Ca}^{2+}$ activates calpain 10, which could cleave protein components of the MPTP (Arrington et al., 2006) resulting in the MPTP opening at a high conductance state, swelling, and rupture of the outer mitochondrial membrane leading to necrotic cell death.

implicated (Scheme 4), but the mechanisms remain unresolved, and a Complex I defect has not been ruled out. We and others have reported that short-chain ceramide could directly suppress respiratory chain Complex III activity (Di Paola et al., 2000; Gudz et al., 1997). Also, ceramide seems to participate in displacement of cytochrome $\mathrm{c}$ from its binding site on Complex III (Yuan et al., 2003) corresponds to an apparent mitochondrial Complex III defect in IR.

\subsection{Reactive Oxygen Species (ROS)}

Free radical formation occurs during cerebral IR. In fact, mitochondria are the major site of production of ROS, and are the likely source for the generation of peroxynitrite, formed from nitric oxide and superoxide during IR (Chan, 2001). Studies in isolated mitochondria indicated that Complex I and III are potential sites of superoxide formation (Votyakova and Reynolds, 2001). Complex III deficiency observed in cerebral IR strongly implicates Complex III as the major and relevant site of ROS generation; however, Complex I remains to be ruled out. Short- 
chain ceramide could increase the generation of ROS in isolated mitochondria (Garcia-Ruiz et al., 1997).

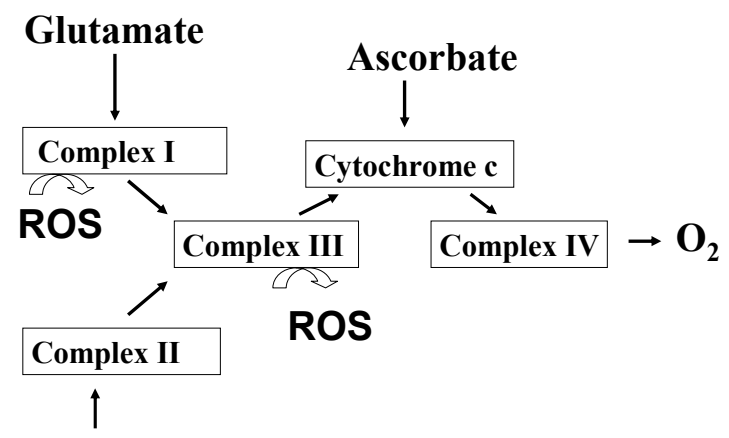

\section{Succinate}

Scheme 4. Mitochondrial respiratory chain complexes. Mitochondrial respiratory chain consists of four multi-protein complexes Complex I-IV. The respiratory chain function is determined using substrates such as glutamate, succinate or ascorbate, which are oxidized via different complexes of respiratory chain. An inhibition of the electron transport through the Complex I or III could result in generation of ROS.

\subsection{Mitochondrial Permeability Transition Pore (MPTP)}

Excessive accumulation of $\mathrm{Ca}^{2+}$ in mitochondrial matrix could trigger opening of the MPTP at a high conductance state that is accompanied with dissipation of transmembrane potential and swelling of mitochondria. In brain mitochondria, $\mathrm{Ca}^{2+}$ may also activate a limited permeability state of MPTP opening that only depolarizes mitochondria without swelling (Novgorodov and Gudz, 1996). This depolarization dramatically reduces the driving force for $\mathrm{Ca}^{2+}$ influx via the uniporter channel in the inner membrane, thus limiting the mitochondrial ability to sequester $\mathrm{Ca}^{2+}$.

MPTP opening at a high conductance state appears to be a crucial event leading to cell death by necrosis (Fiskum, 2000; Galluzzi et al., 2009; Kroemer et al., 1998). Severe insult causes widespread opening of the MPTP in mitochondria. Cell death proceeds through necrosis when the MPTP remains open, causing the inhibition of ATP production. If the initial insult is not too severe and MPTP does not open, cellular ATP can be maintained to support the energy demand of apoptosis. This provides an explanation for the coexistence of apoptotic and necrotic cell death in IR-injured tissue. It has been emphasized that MPTP regulates necrotic, but not apoptotic cell death in cardiac and cerebral IR (Nakagawa et al., 2005; Schinzel et al., 2005). Mice deficient in cyclophilin D (CyD), the main regulatory component of MPTP, developed up to $37 \%$ smaller brain infarcts after IR. CyD-deficient cells died normally in response to various apoptotic stimuli, but were resistant to necrotic cell death induced by ROS and $\mathrm{Ca}^{2+}$ overload. MPTP opening at a high conductance state has been proposed to occur in cerebral IR, but the evidence is largely indirect (Sims and Anderson, 2002; Stavrovskaya and Kristal, 2005). The opening of the MPTP at a high conductance state has been implicated as another mechanism of cytochrome c release from mitochondria due to short-chain ceramide (Arora et al., 1997; Novgorodov et al., 2005; Pastorino et al., 1999a; Szalai et al., 1999). 


\subsection{Release of pro-apoptotic proteins from mitochondria}

Apoptosis is mediated by two major pathways: the extrinsic and the intrinsic (or mitochondrial) pathway. The release of mitochondrial cytochrome c and/or Smac, which antagonizes apoptotic protein inhibitor, into the cytosol initiates the activation of caspase- 9 leading to the proteolytic activation of executioner caspase- 3 and -7 . Cytochrome c release from mitochondria is well documented in different models of ischemia (Galluzzi et al., 2009). Recent studies have showed caspase-independent apoptosis involving the release of mitochondrial proteins, apoptosis-inducing factor (AIF), and endonuclease G (EndoG) and their translocation to the nucleus in brain IR (Galluzzi et al., 2009; Joza et al., 2009). Emerging evidence indicates an important role of Bax in cytochrome $\mathrm{c}$ and Smac (but not AIF and EndoG) release from brain mitochondria (Brustovetsky et al., 2003). Importantly, mitochondrial calpain has been implicated in AIF release from mitochondria (Kar et al.). The release of mitochondrial proteins implies that the outer and /or the inner mitochondrial membrane is compromised in IR, but the precise mechanisms of the protein release remain unclear. Short-chain ceramide accelerated the release of cytochrome $\mathrm{c}$ and AIF from heart mitochondria (Di Paola et al., 2004), and natural $\mathrm{C}_{16}$-ceramide has been shown to form large channels in the outer mitochondrial membrane permeable to cytochrome c (Siskind and Colombini, 2000).

\section{Ceramide and mitochondria in cell death}

Irrespective of the type of IR, IR-related physiological events have a common final consequence: alteration of mitochondrial function and release of mitochondrial proteins, leading to cell death. Cells with hallmarks of necrosis or apoptosis have been detected in animal models of IR ( $\mathrm{Li}$ et al., 1995). The mitochondrial changes appear to be one essential step in tissue damage in IR, and treatments that ameliorate tissue infarction were associated with better recovery of mitochondrial function (Nakai et al., 1997). Multiple studies show intimate connections between ceramide signaling and functioning of mitochondria (Mimeault, 2002; Morales et al., 2007), which play central role in integration of cellular signals to determine the outcome among apoptosis, necrosis, or proliferation (Brenner and Kroemer, 2000; Ferri and Kroemer, 2001; Kroemer et al., 2007).

Several lines of evidence have implicated changes in mitochondrial function as an intermediate step in transduction of ceramide signals that culminate in apoptotic or necrotic cell death (Morales et al., 2007; Taha et al., 2006). First, ceramide-induced apoptosis is accompanied by release of pro-apoptotic proteins from mitochondria (Birbes et al., 2001; Hearps et al., 2002; Zhang et al., 2008), increased generation of mitochondrial ROS (Won and Singh, 2006), and discharge of mitochondrial transmembrane potential, $\Delta \psi$ (Gendron et al., 2001; Hearps et al., 2002; Lin et al., 2004; Zamzami et al., 1995). Second, interventions that specifically prevent mitochondrial dysfunction suppress ceramide-induced apoptosis: inhibitors of the MPTP bongkrekic acid (Gendron et al., 2001; Stoica et al., 2003) and cyclosporin A (Pacher and Hajnoczky, 2001; Pastorino et al., 1996; Stoica et al., 2003); and over-expression of Bcl-2 (Geley et al., 1997; Gendron et al., 2001; Scaffidi et al., 1999; Zamzami et al., 1995; Zhang et al., 1996). Third, TNF-a-, ischemia/reperfusion-, etoposide-, or UV-induced apoptosis is associated with simultaneous increase in mitochondrial ceramide (Birbes et al., 2005; Dai et al., 2004; Garcia-Ruiz et al., 1997; Yu et al., 2007).

Depending on cell type and stimuli, ceramide can alter mitochondrial function indirectly or directly (Scheme 5). Indirectly, ceramide modifies activity of pro-apoptotic and anti- 
apoptotic members of the Bcl-2 family of proteins that, in turn, alter the outer mitochondrial membrane permeability for cytochrome $\mathrm{c}$ and other pro-apoptotic molecules. Protein targets for ceramide in the cytoplasm include protein phosphatases PP1A and PP2A, protein kinases PKC $\zeta$, raf-1, and kinase-suppressor Ras (Snook et al., 2006). In the lysosomal compartment, ceramide activates aspartate protease cathepsin D (Bidere et al., 2003; Heinrich et al., 2004; Heinrich et al., 1999; Pettus et al., 2002). Among these targets, cathepsin D, PP2A, and PP1A could propagate a pro-apoptotic ceramide signal to the level of the mitochondria (Pettus et al., 2002). Interaction of ceramide with cathepsin D results in cleavage of Bid to active tBid with subsequent activation of caspase- 9 and caspase- 3 (Heinrich et al., 2004). Activation by ceramides of serine/threonine protein phosphatase PP2A is involved in regulation of the apoptotic/anti-apoptotic activity of Bcl-2 family proteins by changing their phosphorylation status. Ceramide-activated PP2A increases the pro-apoptotic potential of Bcl-2 family proteins by dephosphorylation of Bax (activation) (Xin and Deng, 2006), or Bcl-2 (inactivation) (Ruvolo et al., 1999). An additional substrate for PP2A is serine/threonine kinase Akt/PKB (Pettus et al., 2002). Ceramide-dependent activation of PP2A leads to inactivation of Akt (Garcia et al., 2003; Millward et al., 1999; Pettus et al., 2002) that, in turn, results in dephosphorylation and activation of pro-apoptotic Bad, an Akt substrate (Datta et al., 1997). At the same time PP2A can directly dephosphorylate Bad, thus increasing its pro-apoptotic activity (Chiang et al., 2003). PP1A also can exert its effect on mitochondria by Bad dephosphorylation (Garcia et al., 2003). Interestingly, ceramide by itself can trigger transition of Bax into the active conformation, insertion in to the outer mitochondrial membrane with the subsequent release of cytochrome c and Smac in a cell-free system (Kashkar et al., 2005). Potentiation of Bax binding by ceramides to the outer mitochondrial membrane was shown by Birbes and colleagues (Birbes et al., 2005) and in energized mitochondria ceramide-induced Baxdependent MPTP opening (Pastorino et al., 1999b). Critical involvement of ceramide in triggering Bax translocation to the mitochondria was demonstrated during hypoxia/reoxygenation in neuronal cells (Jin et al., 2008). Attenuation of Bax translocation by knockdown of ceramide synthase CerS5 or aSMase suggests contribution of the activated salvage pathway in ceramide upregulation; however, the mechanisms by which ceramide exerts its effect remain unknown.

Less-defined, indirect mechanisms include interaction of ceramide with protein kinases PKC $\delta$, p38 and JNK. Short-chain ceramides induce translocation of PKC $\delta$ from the cytoplasm to the mitochondria in LNCaP cells (Sumitomo et al., 2002). The translocation of PKC $\delta$ was accompanied by cytochrome c release. Mitochondrial translocation of PKC $\delta$ and activation of kinase activity was also evident when endogenous ceramides were raised by activation of de novo and neutral SMase-dependent pathways of ceramide production. Endogenous ceramide-induced PKC $\delta$ translocation similarly promoted release of cytochrome $c$ and caspase-9 activation. A report by Huwiler et al. (Huwiler et al., 1998) indicates that ceramide can directly target PKC $\delta$. Thus, increased ceramide during I/R can potentially contribute to mitochondrial translocation/activation of PKC $\delta$, which enhances cytochrome c release in heart I/R (Murriel et al., 2004). Although potential mitochondrial PKC $\delta$ targets for which phosphorylation results in cytochrome $\mathrm{c}$ release remain illusive, PKC $\delta$-dependant accumulation and dephosphorylation of Bad may contribute to the initiation of apoptotic program (Murriel et al., 2004).

The member of the mitogen-activated protein kinase (MAPK) superfamily p38 MAPK was implicated in ceramide-induced apoptosis in cardiomyocytes (Kong et al., 2005). Short-chain 


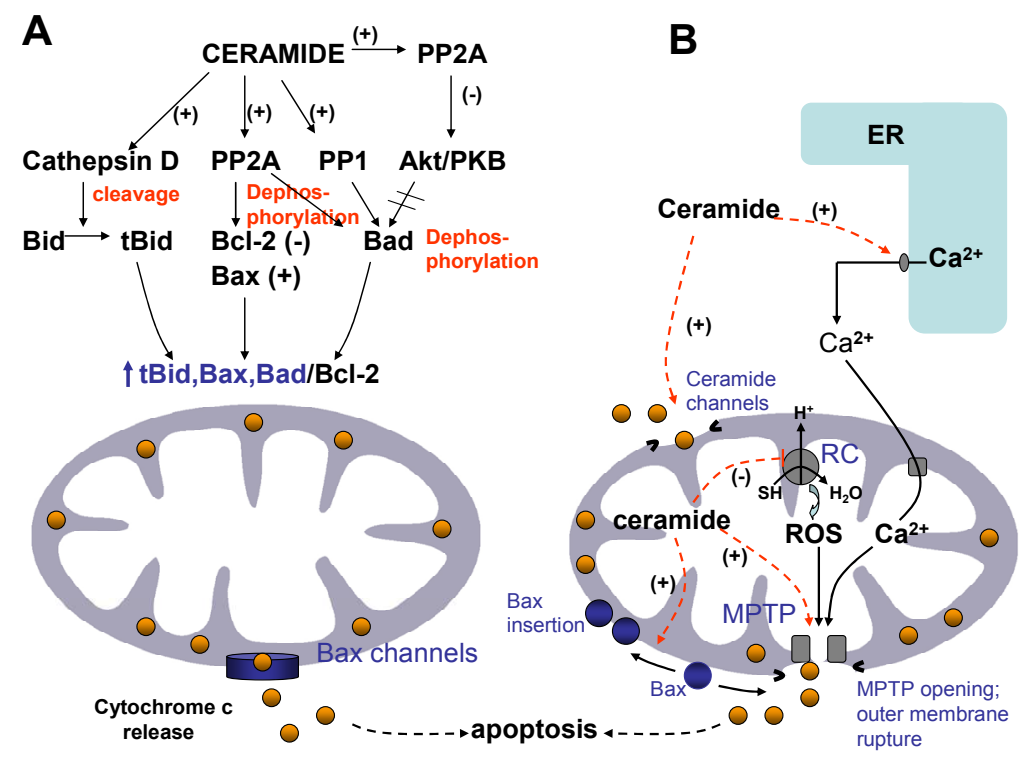

Scheme 5. Ceramide modulates mitochondrial functions through direct and indirect mechanisms. A. Indirect modulation of mitochondrial functions by ceramide occurs through the change in the ratio of pro-apoptotic/anti-apoptotic proteins of Bcl-2 family at the outer mitochondrial membrane. B. Direct modulation of mitochondrial functions by ceramide include a) formation of ceramide channels permeable for cytochrome $\mathrm{c}$ in the outer mitochondrial membrane; b) potentiation of mitochondrial permeability transition pore opening (MPTP) in the inner membrane in the presence of $\mathrm{Ca}^{2+}$ or Bax (ceramide-induced $\mathrm{Ca}^{2+}$ release from the endoplasmic reticulum (ER) can contribute to the processes; $\mathrm{c}$ ) potentiation of Bax insertion (activation) in to the outer membrane, $d$ ) inhibition of the respiratory chain $(\mathrm{RC})$ with a subsequent increase in ROS formation.

ceramide treatment induced phosphorylation/activation of p38 MAPK which was accompanied by release of cytochrome $c$ from the mitochondria and by the discharge of mitochondrial membrane potential. P38 MAPK inhibitor, SB 202190, abrogated the effect of ceramide both on p38 MAPK phosphorylation and on mitochondrial dysfunction. An interesting aspect of the study was the phosphorylation of the mitochondria-associated p38 MAPK pool under the influence of ceramide. This observation might indicate local signaling in mitochondria-mediated cell death. Although mitochondria-related targets for ceramideactivated p38 MAPK are not well defined, a recent report by Capano and Crompton (Capano and Crompton, 2006) demonstrates that activation of p38 MAPK during simulated ischemia in cardiomyocytes is a key regulatory point of Bax translocation from the cytosol to the mitochondria. The evidence of p38 MAPK-dependent phosphorylation of BimeL in apoptotic cell response has been provided (Cai et al., 2006). Another member of the MAPK superfamily, JNK, was shown to be readily activated by both endogenous ceramide generation in liver I/R (Llacuna et al., 2006) and by addition of exogenous ceramide (Kurinna et al., 2004). Activated JNK translocates to the mitochondria and initiates cytochrome c release and cell death by yet unidentified mechanisms (Eminel et al., 2004; 
Kurinna et al., 2004); however, direct interaction of JNK with the mitochondrial pool of Bcl$x \mathrm{~L}$ was suggested (Kharbanda et al., 2000). Alternatively, activated JNK can induce mitochondrial dysfunction by phosphorylation of a pro-apoptotic member of the Bcl-2 family protein, Bim (Kurinna et al., 2004; Lei and Davis, 2003; Llacuna et al., 2006). Translocation of activated Bim to mitochondria initiates Bax-dependent cytochrome $\mathrm{c}$ release and apoptosis (Lei and Davis, 2003). Several other members of Bcl-2 family proteins have been proposed to mediate pro-apoptotic JNK signaling(Weston and Davis, 2007). Overall, the increased ratio of pro-apoptotic/anti-apoptotic proteins bound to mitochondria is generally considered to trigger permeabilization of the outer mitochondrial membrane for cytochrome $c$ and other mitochondrial inter-membrane resident proteins, initiators of apoptosis (Armstrong, 2006; Kroemer et al., 2007). The increases in cell ceramide species contents are expected to contribute to the induction of apoptosis by this mechanism. Among non-protein indirect pathways, those associated with $\mathrm{Ca}^{2+}$ signaling attract special attention because of the well-known ability of these organelles both to respond to $\mathrm{Ca}^{2+}$ and to shape and propagate the $\mathrm{Ca}^{2+}$ signal within the cell (Giorgi et al., 2008; Szabadkai and Duchen, 2008). In this pathway, the $\mathrm{Ca}^{2+}$ pool of the ER is a target for ceramide (Pinton et al., 2001; Scorrano et al., 2003). $\mathrm{Ca}^{2+}$ released by ceramide from the ER is readily accumulated in mitochondria that, in turn, results in MPTP opening, and cytochrome c release.

Evidence is also accruing to implicate a direct action of ceramide on mitochondria. In this context, modulation by ceramide of mitochondrial functions at the level of isolated organelles has provided further evidence in support of this mechanism. It has been reported that ceramides directly suppress respiratory chain activity at the level of respiratory chain Complex III and/or Complex I (Di Paola et al., 2000; Garcia-Ruiz et al., 1997; Gudz et al., 1997; Yu et al., 2007). Suppression of the respiratory chain by ceramides results in increased production of ROS (Andrieu-Abadie et al., 2001; Di Paola et al., 2000; Garcia-Ruiz et al., 1997; Quillet-Mary et al., 1997), well-known inducers of an apoptotic cell response (AndrieuAbadie et al., 2001; Ott et al., 2007). Increased ROS production by endothelial cells after hypoxia/reoxygenation was linked to the ceramide-induced suppression of the mitochondrial respiratory chain (Therade-Matharan et al., 2005).

Moreover, current research is focused on the ability of ceramides to release cytochrome c or other pro-apoptotic proteins from the mitochondrial inter-membrane space. Within the model of Colombini and co-workers, pro-apoptotic protein release is due to formation of large pores in the outer mitochondrial membrane by ceramide itself, whereas the inner membrane is viewed as being ceramide-insensitive. This model is supported by extensive experimental material using isolated mitochondria (Di Paola et al., 2004; Ghafourifar et al., 1999; Siskind et al., 2002, 2006) and artificial membranes (liposomes and black lipid membranes) (Montes et al., 2002; Siskind et al., 2002). Importantly, it was recently shown that anti-apoptotic Bcl-2 can disassemble ceramide channels in the outer mitochondrial membrane and black lipid membranes (Siskind et al., 2008), thus providing the mechanistic explanation for the original observation of Ghafourifar et al. (Ghafourifar et al., 1999) that Bcl-2 suppresses ceramide-induced cytochrome c release from isolated mitochondria. However, the formation of ceramide channels seems to be highly dependent on the conditions employed, and has been questioned in a number of publications (Kristal and Brown, 1999; Novgorodov et al., 2005; Szalai et al., 1999; Yuan H, 2003). Besides, a few reports suggest that the permeabilization of the inner mitochondrial membrane via the opening of the MPTP could be a primary event in initiation of cytochrome c release in the presence of ceramides (Pastorino et al., 1999b; Szalai et al., 1999). The switch between 
selective permeabilization of the outer membrane vs. permeabilization of the inner membrane in the presence of ceramide appears to depend on the composition of incubation medium and the nature of ceramide employed (Di Paola et al., 2004).

Additional direct effects of ceramide on mitochondria include modulation of the ionic permeability of the lipid component of the inner membrane (Di Paola et al., 2000) and displacement of cytochrome $\mathrm{c}$ from the inner membrane as a result of the direct interaction with the proteins in the respiratory chain Complex III (Ghafourifar et al., 1999; Yuan H, 2003). Emerging evidence suggests involvement of ceramides in reorganization of the mitochondrial network. Both exogenous and endogenously generated ceramides induce mitochondrial fission (Parra et al., 2008; Zeidan et al., 2008), which may contribute to apoptotic cell death (Suen et al., 2008). What particular effectors of mitochondrial fission (DRP1, Fis1, or Bax) or fusion (OPA-1, Mitofusins) machineries are the targets of ceramide in this process remains to be determined. However, in cardiomyocytes exposed to exogenous $\mathrm{C}_{2}$-ceramide, an increased expression of mitochondrial resident Fis1 and enhanced recruitment of cytosolic DRP1 to mitochondrial fission foci may contribute to disintegration of the mitochondrial network (Parra et al., 2008).

It should be appreciated that the ceramide/mitochondria interaction in the control of apoptosis should be considered in conjunction with the effects of its pro-apoptotic metabolites such as ganglioside GD3 and sphingosine. GD3 shares with ceramide the same properties with respect to its effects on isolated mitochondria and mitochondria in situ. In cells, it disrupts mitochondrial membrane potential in a Bcl-2-sensitive manner (Rippo et al., 2000) and induces ROS production (Colell et al., 2001). At the level of isolated mitochondria, it inhibits the mitochondrial respiratory chain at the level of Complex III (Scorrano et al., 1999), increases ROS production (Garcia-Ruiz et al., 2000), opens the MPTP with the subsequent release of cytochrome c (Inoki et al., 2000; Kristal and Brown, 1999; Scorrano et al., 1999), and potentiates interaction of Bax with mitochondria (Pastorino et al., 1999b). Interestingly, while the effect of CD3 on ROS production is relatively nonspecific (lactosylceramide, GM1, GD1a and glucosylceramide produce a similar response (GarciaRuiz et al., 1997)), the effect of GD3 in the induction of apoptosis and MPTP opening shows considerable specificity. GM3, GM1 GD1, GD1a, GT1 has no or a slight inhibitory effect (Kristal and Brown, 1999; Pastorino et al., 1999b; Scorrano et al., 1999). In some instances, the effect of ceramide on mitochondria in cells can be explained by its conversion to GD3 (De Maria et al., 1997; Rippo et al., 2000).

Another pro-apoptotic ceramide derivative, sphingosine, releases cytochrome c from mitochondria that could be inhibited by over-expression of anti-apoptotic Bcl-xL (Cuvillier et al., 2000). In contrast to ceramides and GD3, sphingosine suppresses the MPTP in isolated mitochondria, and thus MPTP-dependent cytochrome c release (Broekemeier and Pfeiffer, 1995; Scorrano et al., 2001). It also inhibits ceramide channel formation in the outer mitochondrial membrane (Elrick et al., 2006). This indicates that indirect pathways of cytochrome c release, for example, by recruitment of Bax to mitochondria (Phillips et al., 2007), are predominant in the action of sphingosine on mitochondria. At the same time, similar to ceramide, sphingosine suppresses respiratory chain activity (Hassoun et al., 2006) and increases ROS production by mitochondria, although at higher concentrations (GarciaRuiz et al., 1997). Interaction of ceramide, sphingosine, and ganglioside pathways in the control of mitochondrial functions in the time-course of apoptosis remains to be established. 
Thus, the proposed mechanisms by which ceramides may affect mitochondria vary, and the combination of direct and indirect mechanisms involved in propagation of ceramide signals to mitochondria depends on cell type and the nature of the stimuli employed.

\section{Conclusion}

A cardinal feature of brain tissue injury in stroke is mitochondrial dysfunction and the release of mitochondrial proteins leading to cell death. It has become increasingly clear that ceramide, a membrane sphingolipid and a key mediator of cell-stress responses, could play a critical role in cerebral IR - induced mitochondrial injury. Mitochondria are being appreciated as vital intracellular compartments for ceramide metabolism in cerebral IR. Emerging data suggest that the subcellular location of ceramide generation plays a fundamental role in dictating its downstream targets and cell responses to stress stimuli. Continued research efforts are required to better understand the pathophysiological mechanisms of cerebral IR injury, to identify and test new protective agents. Further studies of the molecular basis of the role of ceramide in the ischemic brain are warranted. Because many assumptions regarding ceramide functions in IR-induced tissue injury were based on in vitro studies employing artificial ceramides, we must critically evaluate the mitochondrial dysfunctions in IR-injured brain and define a possible role of long-chain ceramides as causes of the mitochondrial impairment. This will allow the discovery of novel and groundbreaking therapeutic approaches to mitigate diseases that may result from elevations in ceramide and its metabolites.

\section{Acknowledgements}

We thank Dr. Jennifer G. Schnellmann for help with preparation of the manuscript. This work is supported by the NIH/NCCR COBRE in Lipidomics and Pathobiology P20 RR 17677 (TIG), VA Merit Awards from BLRD and RRD Service (TIG), and SAN was supported by NIH grant AG16583.

\section{References}

Andreyev, A.Y., Fahy, E., Guan, Z., Kelly, S., Li, X., McDonald, J.G., Milne, S., Myers, D., Park, H., Ryan, A., et al. (2010). Subcellular organelle lipidomics in TLR-4-activated macrophages. J Lipid Res 51, 2785-2797.

Andrieu-Abadie, N., Gouaze, V., Salvayre, R., and Levade, T. (2001). Ceramide in apoptosis signaling: relationship with oxidative stress. Free Radic Biol Med 31, 717-728.

Ardail, D., Popa, I., Alcantara, K., Pons, A., Zanetta, J.P., Louisot, P., Thomas, L., and Portoukalian, J. (2001). Occurrence of ceramides and neutral glycolipids with unusual long-chain base composition in purified rat liver mitochondria. FEBS letters 488, 160-164.

Argaud, L., Prigent, A.F., Chalabreysse, L., Loufouat, J., Lagarde, M., and Ovize, M. (2004). Ceramide in the antiapoptotic effect of ischemic preconditioning. American journal of physiology 286, H246-251.

Armstrong, J.S. (2006). Mitochondrial membrane permeabilization: the sine qua non for cell death. Bioessays 28, 253-260. 
Arora, A.S., Jones, B.J., Patel, T.C., Bronk, S.F., and Gores, G.J. (1997). Ceramide induces hepatocyte cell death through disruption of mitochondrial function in the rat. Hepatology 25, 958-963.

Arrington, D.D., Van Vleet, T.R., and Schnellmann, R.G. (2006). Calpain 10: a mitochondrial calpain and its role in calcium-induced mitochondrial dysfunction. American journal of physiology 291, C1159-1171.

Atlante, A., Giannattasio, S., Bobba, A., Gagliardi, S., Petragallo, V., Calissano, P., Marra, E., and Passarella, S. (2005). An increase in the ATP levels occurs in cerebellar granule cells en route to apoptosis in which ATP derives from both oxidative phosphorylation and anaerobic glycolysis. Biochimica et biophysica acta 1708, 5062.

Beresewicz, A., Dobrzyn, A., and Gorski, J. (2002). Accumulation of specific ceramides in ischemic/reperfused rat heart; effect of ischemic preconditioning. J Physiol Pharmacol 53, 371-382.

Bianchi, P., Kunduzova, O., Masini, E., Cambon, C., Bani, D., Raimondi, L., Seguelas, M.H., Nistri, S., Colucci, W., Leducq, N., et al. (2005). Oxidative stress by monoamine oxidase mediates receptor-independent cardiomyocyte apoptosis by serotonin and postischemic myocardial injury. Circulation 112, 3297-3305.

Bidere, N., Lorenzo, H.K., Carmona, S., Laforge, M., Harper, F., Dumont, C., and Senik, A. (2003). Cathepsin D triggers Bax activation, resulting in selective apoptosisinducing factor (AIF) relocation in T lymphocytes entering the early commitment phase to apoptosis. The Journal of biological chemistry 278, 31401-31411.

Bielawska, A., Perry, D.K., and Hannun, Y.A. (2001). Determination of ceramides and diglycerides by the diglyceride kinase assay. Analytical biochemistry 298, 141-150.

Bielawska, A.E., Shapiro, J.P., Jiang, L., Melkonyan, H.S., Piot, C., Wolfe, C.L., Tomei, L.D., Hannun, Y.A., and Umansky, S.R. (1997). Ceramide is involved in triggering of cardiomyocyte apoptosis induced by ischemia and reperfusion. The American journal of pathology 151, 1257-1263.

Bionda, C., Portoukalian, J., Schmitt, D., Rodriguez-Lafrasse, C., and Ardail, D. (2004). Subcellular compartmentalization of ceramide metabolism: MAM (mitochondriaassociated membrane) and/or mitochondria? The Biochemical journal 382, 527-533.

Birbes, H., El Bawab, S., Hannun, Y.A., and Obeid, L.M. (2001). Selective hydrolysis of a mitochondrial pool of sphingomyelin induces apoptosis. Faseb J 15, 2669-2679.

Birbes, H., Luberto, C., Hsu, Y.T., El Bawab, S., Hannun, Y.A., and Obeid, L.M. (2005). A mitochondrial pool of sphingomyelin is involved in TNFalpha-induced Bax translocation to mitochondria. The Biochemical journal 386, 445-451.

Bollinger, C.R., Teichgraber, V., and Gulbins, E. (2005). Ceramide-enriched membrane domains. Biochimica et biophysica acta 1746, 284-294.

Bradham, C.A., Stachlewitz, R.F., Gao, W., Qian, T., Jayadev, S., Jenkins, G., Hannun, Y., Lemasters, J.J., Thurman, R.G., and Brenner, D.A. (1997). Reperfusion after liver transplantation in rats differentially activates the mitogen-activated protein kinases. Hepatology (Baltimore, Md 25, 1128-1135.

Brenner, C., and Kroemer, G. (2000). Apoptosis. Mitochondria--the death signal integrators. Science 289, 1150-1151. 
Broekemeier, K.M., and Pfeiffer, D.R. (1995). Inhibition of the mitochondrial permeability transition by cyclosporin A during long time frame experiments: relationship between pore opening and the activity of mitochondrial phospholipases. Biochemistry 34, 16440-16449.

Brustovetsky, N., and Dubinsky, J.M. (2000a). Dual responses of CNS mitochondria to elevated calcium. J Neurosci 20, 103-113.

Brustovetsky, N., and Dubinsky, J.M. (2000b). Limitations of cyclosporin A inhibition of the permeability transition in CNS mitochondria. J Neurosci 20, 8229-8237.

Brustovetsky, N., Dubinsky, J.M., Antonsson, B., and Jemmerson, R. (2003). Two pathways for tBID-induced cytochrome $\mathrm{c}$ release from rat brain mitochondria: BAK- versus BAX-dependence. Journal of neurochemistry 84, 196-207.

Cai, B., Chang, S.H., Becker, E.B., Bonni, A., and Xia, Z. (2006). p38 MAP kinase mediates apoptosis through phosphorylation of BimEL at Ser-65. The Journal of biological chemistry 281, 25215-25222.

Capano, M., and Crompton, M. (2006). Bax translocates to mitochondria of heart cells during simulated ischaemia: involvement of AMP-activated and p38 mitogen-activated protein kinases. The Biochemical journal 395, 57-64.

Chan, P.H. (2001). Reactive oxygen radicals in signaling and damage in the ischemic brain. J Cereb Blood Flow Metab 21, 2-14.

Chan, P.H. (2004). Future targets and cascades for neuroprotective strategies. Stroke 35, 2748-2750.

Chatelut, M., Leruth, M., Harzer, K., Dagan, A., Marchesini, S., Gatt, S., Salvayre, R., Courtoy, P., and Levade, T. (1998). Natural ceramide is unable to escape the lysosome, in contrast to a fluorescent analogue. FEBS letters 426, 102-106.

Chen, Y., Ginis, I., and Hallenbeck, J.M. (2001). The protective effect of ceramide in immature rat brain hypoxia-ischemia involves up-regulation of bcl-2 and reduction of TUNEL-positive cells. J Cereb Blood Flow Metab 21, 34-40.

Chiang, C.W., Kanies, C., Kim, K.W., Fang, W.B., Parkhurst, C., Xie, M., Henry, T., and Yang, E. (2003). Protein phosphatase 2A dephosphorylation of phosphoserine 112 plays the gatekeeper role for BAD-mediated apoptosis. Molecular and cellular biology 23, 6350-6362.

Chudakova, D.A., Zeidan, Y.H., Wheeler, B.W., Yu, J., Novgorodov, S.A., Kindy, M.S., Hannun, Y.A., and Gudz, T.I. (2008). Integrin-associated Lyn kinase promotes cell survival by suppressing acid sphingomyelinase activity. The Journal of biological chemistry.

Clarke, C.J., Snook, C.F., Tani, M., Matmati, N., Marchesini, N., and Hannun, Y.A. (2006). The extended family of neutral sphingomyelinases. Biochemistry 45, 11247-11256.

Clarke, C.J., Wu, B.X., and Hannun, Y.A. (2011). The neutral sphingomyelinase family: identifying biochemical connections. Advances in enzyme regulation 51, 51-58.

Colell, A., Garcia-Ruiz, C., Roman, J., Ballesta, A., and Fernandez-Checa, J.C. (2001). Ganglioside GD3 enhances apoptosis by suppressing the nuclear factor-kappa Bdependent survival pathway. Faseb J 15, 1068-1070.

Contreras, F.X., Sanchez-Magraner, L., Alonso, A., and Goni, F.M. (2010). Transbilayer (flipflop) lipid motion and lipid scrambling in membranes. FEBS letters 584, 1779-1786. 
Cordis, G.A., Yoshida, T., and Das, D.K. (1998). HPTLC analysis of sphingomylein, ceramide and sphingosine in ischemic/reperfused rat heart. Journal of pharmaceutical and biomedical analysis 16, 1189-1193.

Cui, J., Engelman, R.M., Maulik, N., and Das, D.K. (2004). Role of ceramide in ischemic preconditioning. Journal of the American College of Surgeons 198, 770-777.

Cuvillier, O., Edsall, L., and Spiegel, S. (2000). Involvement of sphingosine in mitochondriadependent Fas-induced apoptosis of type II Jurkat T cells. The Journal of biological chemistry 275, 15691-15700.

D'Mello N, P., Childress, A.M., Franklin, D.S., Kale, S.P., Pinswasdi, C., and Jazwinski, S.M. (1994). Cloning and characterization of LAG1, a longevity-assurance gene in yeast. The Journal of biological chemistry 269, 15451-15459.

Dai, Q., Liu, J., Chen, J., Durrant, D., McIntyre, T.M., and Lee, R.M. (2004). Mitochondrial ceramide increases in UV-irradiated HeLa cells and is mainly derived from hydrolysis of sphingomyelin. Oncogene 23, 3650-3658.

Datta, S.R., Dudek, H., Tao, X., Masters, S., Fu, H., Gotoh, Y., and Greenberg, M.E. (1997). Akt phosphorylation of BAD couples survival signals to the cell-intrinsic death machinery. Cell 91, 231-241.

De Maria, R., Lenti, L., Malisan, F., d'Agostino, F., Tomassini, B., Zeuner, A., Rippo, M.R., and Testi, R. (1997). Requirement for GD3 ganglioside in CD95- and ceramideinduced apoptosis. Science 277, 1652-1655.

Deng, X., Yin, X., Allan, R., Lu, D.D., Maurer, C.W., Haimovitz-Friedman, A., Fuks, Z., Shaham, S., and Kolesnick, R. (2008). Ceramide biogenesis is required for radiationinduced apoptosis in the germ line of C. elegans. Science 322, 110-115.

Der, P., Cui, J., and Das, D.K. (2006). Role of lipid rafts in ceramide and nitric oxide signaling in the ischemic and preconditioned hearts. Journal of molecular and cellular cardiology 40, 313-320.

Di Paola, M., Cocco, T., and Lorusso, M. (2000). Ceramide interaction with the respiratory chain of heart mitochondria. Biochemistry 39, 6660-6668.

Di Paola, M., Zaccagnino, P., Montedoro, G., Cocco, T., and Lorusso, M. (2004). Ceramide induces release of pro-apoptotic proteins from mitochondria by either a Ca2+ dependent or a Ca2+ -independent mechanism. J Bioenerg Biomembr 36, 165-170.

El Bawab, S., Birbes, H., Roddy, P., Szulc, Z.M., Bielawska, A., and Hannun, Y.A. (2001). Biochemical characterization of the reverse activity of rat brain ceramidase. A CoAindependent and fumonisin B1-insensitive ceramide synthase. The Journal of biological chemistry 276, 16758-16766.

El Bawab, S., Roddy, P., Qian, T., Bielawska, A., Lemasters, J.J., and Hannun, Y.A. (2000). Molecular cloning and characterization of a human mitochondrial ceramidase. The Journal of biological chemistry 275, 21508-21513.

Elrick, M.J., Fluss, S., and Colombini, M. (2006). Sphingosine, a product of ceramide hydrolysis, influences the formation of ceramide channels. Biophysical journal 91, 1749-1756.

Eminel, S., Klettner, A., Roemer, L., Herdegen, T., and Waetzig, V. (2004). JNK2 translocates to the mitochondria and mediates cytochrome c release in PC12 cells in response to 6-hydroxydopamine. The Journal of biological chemistry 279, 55385-55392. 
Ferri, K.F., and Kroemer, G. (2001). Organelle-specific initiation of cell death pathways. Nat Cell Biol 3, E255-263.

Fiskum, G. (2000). Mitochondrial participation in ischemic and traumatic neural cell death. J Neurotrauma 17, 843-855.

Furuya, K., Ginis, I., Takeda, H., Chen, Y., and Hallenbeck, J.M. (2001). Cell permeable exogenous ceramide reduces infarct size in spontaneously hypertensive rats supporting in vitro studies that have implicated ceramide in induction of tolerance to ischemia. J Cereb Blood Flow Metab 21, 226-232.

Futerman, A.H. (2006). Intracellular trafficking of sphingolipids: relationship to biosynthesis. Biochimica et biophysica acta 1758, 1885-1892.

Futerman, A.H., and Riezman, H. (2005). The ins and outs of sphingolipid synthesis. Trends Cell Biol 15, 312-318.

Futerman, A.H., Stieger, B., Hubbard, A.L., and Pagano, R.E. (1990). Sphingomyelin synthesis in rat liver occurs predominantly at the cis and medial cisternae of the Golgi apparatus. The Journal of biological chemistry 265, 8650-8657.

Galluzzi, L., Blomgren, K., and Kroemer, G. (2009). Mitochondrial membrane permeabilization in neuronal injury. Nat Rev Neurosci 10, 481-494.

Garcia-Ruiz, C., Colell, A., Mari, M., Morales, A., and Fernandez-Checa, J.C. (1997). Direct effect of ceramide on the mitochondrial electron transport chain leads to generation of reactive oxygen species. Role of mitochondrial glutathione. The Journal of biological chemistry 272, 11369-11377.

Garcia-Ruiz, C., Colell, A., Paris, R., and Fernandez-Checa, J.C. (2000). Direct interaction of GD3 ganglioside with mitochondria generates reactive oxygen species followed by mitochondrial permeability transition, cytochrome c release, and caspase activation. Faseb J 14, 847-858.

Garcia, A., Cayla, X., Guergnon, J., Dessauge, F., Hospital, V., Rebollo, M.P., Fleischer, A., and Rebollo, A. (2003). Serine/threonine protein phosphatases PP1 and PP2A are key players in apoptosis. Biochimie 85, 721-726.

Geley, S., Hartmann, B.L., and Kofler, R. (1997). Ceramides induce a form of apoptosis in human acute lymphoblastic leukemia cells that is inhibited by Bcl-2, but not by CrmA. FEBS letters 400, 15-18.

Gendron, M.C., Schrantz, N., Metivier, D., Kroemer, G., Maciorowska, Z., Sureau, F., Koester, S., and Petit, P.X. (2001). Oxidation of pyridine nucleotides during Fasand ceramide-induced apoptosis in Jurkat cells: correlation with changes in mitochondria, glutathione depletion, intracellular acidification and caspase 3 activation. The Biochemical journal 353, 357-367.

Ghafourifar, P., Klein, S.D., Schucht, O., Schenk, U., Pruschy, M., Rocha, S., and Richter, C. (1999). Ceramide induces cytochrome c release from isolated mitochondria. Importance of mitochondrial redox state. The Journal of biological chemistry 274, 6080-6084.

Ginis, I., Schweizer, U., Brenner, M., Liu, J., Azzam, N., Spatz, M., and Hallenbeck, J.M. (1999). TNF-alpha pretreatment prevents subsequent activation of cultured brain cells with TNF-alpha and hypoxia via ceramide. Am J Physiol 276, C1171-1183. 
Giorgi, C., Romagnoli, A., Pinton, P., and Rizzuto, R. (2008). Ca2+ signaling, mitochondria and cell death. Current molecular medicine 8, 119-130.

Goni, F.M., Contreras, F.X., Montes, L.R., Sot, J., and Alonso, A. (2005). Biophysics (and sociology) of ceramides. Biochemical Society symposium, 177-188.

Graham, T.R., and Kozlov, M.M. (2010). Interplay of proteins and lipids in generating membrane curvature. Current opinion in cell biology 22, 430-436.

Gudz, T.I., Tserng, K.Y., and Hoppel, C.L. (1997). Direct inhibition of mitochondrial respiratory chain complex III by cell-permeable ceramide. The Journal of biological chemistry 272, 24154-24158.

Gustafsson, A.B., and Gottlieb, R.A. (2008). Eat your heart out: Role of autophagy in myocardial ischemia/reperfusion. Autophagy 4, 416-421.

Hait, N.C., Oskeritzian, C.A., Paugh, S.W., Milstien, S., and Spiegel, S. (2006). Sphingosine kinases, sphingosine 1-phosphate, apoptosis and diseases. Biochimica et biophysica acta 1758, 2016-2026.

Hanada, K., Kumagai, K., Yasuda, S., Miura, Y., Kawano, M., Fukasawa, M., and Nishijima, M. (2003). Molecular machinery for non-vesicular trafficking of ceramide. Nature 426, 803-809.

Hannun, Y.A., and Obeid, L.M. (2002). The Ceramide-centric universe of lipid-mediated cell regulation: stress encounters of the lipid kind. The Journal of biological chemistry $277,25847-25850$.

Hannun, Y.A., and Obeid, L.M. (2008). Principles of bioactive lipid signalling: lessons from sphingolipids. Nature reviews 9, 139-150.

Hannun, Y.A., and Obeid, L.M. (2011). Many Ceramides. The Journal of biological chemistry.

Hassoun, S.M., Lancel, S., Petillot, P., Decoster, B., Favory, R., Marchetti, P., and Neviere, R. (2006). Sphingosine impairs mitochondrial function by opening permeability transition pore. Mitochondrion 6, 149-154.

Hearps, A.C., Burrows, J., Connor, C.E., Woods, G.M., Lowenthal, R.M., and Ragg, S.J. (2002). Mitochondrial cytochrome c release precedes transmembrane depolarisation and caspase- 3 activation during ceramide-induced apoptosis of Jurkat $\mathrm{T}$ cells. Apoptosis 7, 387-394.

Heinrich, M., Neumeyer, J., Jakob, M., Hallas, C., Tchikov, V., Winoto-Morbach, S., Wickel, M., Schneider-Brachert, W., Trauzold, A., Hethke, A., et al. (2004). Cathepsin D links TNF-induced acid sphingomyelinase to Bid-mediated caspase- 9 and -3 activation. Cell Death Differ 11, 550-563.

Heinrich, M., Wickel, M., Schneider-Brachert, W., Sandberg, C., Gahr, J., Schwandner, R., Weber, T., Saftig, P., Peters, C., Brunner, J., et al. (1999). Cathepsin D targeted by acid sphingomyelinase-derived ceramide. Embo J 18, 5252-5263.

Hernandez, O.M., Discher, D.J., Bishopric, N.H., and Webster, K.A. (2000). Rapid activation of neutral sphingomyelinase by hypoxia-reoxygenation of cardiac myocytes. Circulation research 86, 198-204.

Hirschberg, K., Rodger, J., and Futerman, A.H. (1993). The long-chain sphingoid base of sphingolipids is acylated at the cytosolic surface of the endoplasmic reticulum in rat liver. The Biochemical journal 290 ( Pt 3), 751-757. 
Huwiler, A., Fabbro, D., and Pfeilschifter, J. (1998). Selective ceramide binding to protein kinase C-alpha and -delta isoenzymes in renal mesangial cells. Biochemistry 37, 14556-14562.

Inoki, Y., Miura, T., Kajimoto, T., Kawase, M., Kawase, Y., Yoshida, Y., Tsuji, S., Kinouchi, T., Endo, H., Kagawa, Y., et al. (2000). Ganglioside GD3 and its mimetics induce cytochrome c release from mitochondria. Biochemical and biophysical research communications 276, 1210-1216.

Jin, J., Hou, Q., Mullen, T.D., Zeidan, Y.H., Bielawski, J., Kraveka, J.M., Bielawska, A., Obeid, L.M., Hannun, Y.A., and Hsu, Y.T. (2008). Ceramide generated by sphingomyelin hydrolysis and the salvage pathway is involved in hypoxia/reoxygenation-induced Bax redistribution to mitochondria in NT-2 cells. The Journal of biological chemistry.

Joza, N., Pospisilik, J.A., Hangen, E., Hanada, T., Modjtahedi, N., Penninger, J.M., and Kroemer, G. (2009). AIF: not just an apoptosis-inducing factor. Annals of the New York Academy of Sciences 1171, 2-11.

Kalhorn, T., and Zager, R.A. (1999). Renal cortical ceramide patterns during ischemic and toxic injury: assessments by HPLC-mass spectrometry. The American journal of physiology 277, F723-733.

Kar, P., Samanta, K., Shaikh, S., Chowdhury, A., Chakraborti, T., and Chakraborti, S. Mitochondrial calpain system: an overview. Archives of biochemistry and biophysics 495, 1-7.

Kashkar, H., Wiegmann, K., Yazdanpanah, B., Haubert, D., and Kronke, M. (2005). Acid sphingomyelinase is indispensable for UV light-induced Bax conformational change at the mitochondrial membrane. The Journal of biological chemistry 280, 20804-20813.

Kharbanda, S., Saxena, S., Yoshida, K., Pandey, P., Kaneki, M., Wang, Q., Cheng, K., Chen, Y.N., Campbell, A., Sudha, T., et al. (2000). Translocation of SAPK/JNK to mitochondria and interaction with $\mathrm{Bcl}-\mathrm{x}(\mathrm{L})$ in response to DNA damage. The Journal of biological chemistry 275, 322-327.

Kirichok, Y., Krapivinsky, G., and Clapham, D.E. (2004). The mitochondrial calcium uniporter is a highly selective ion channel. Nature 427, 360-364.

Kitagaki, H., Cowart, L.A., Matmati, N., Vaena de Avalos, S., Novgorodov, S.A., Zeidan, Y.H., Bielawski, J., Obeid, L.M., and Hannun, Y.A. (2007). Isc1 regulates sphingolipid metabolism in yeast mitochondria. Biochim Biophys Acta 1768, 28492861.

Kitatani, K., Idkowiak-Baldys, J., Bielawski, J., Taha, T.A., Jenkins, R.W., Senkal, C.E., Ogretmen, B., Obeid, L.M., and Hannun, Y.A. (2006). Protein kinase C-induced activation of a ceramide/protein phosphatase 1 pathway leading to dephosphorylation of p38 MAPK. The Journal of biological chemistry 281, 3679336802.

Kitatani, K., Idkowiak-Baldys, J., and Hannun, Y.A. (2008). The sphingolipid salvage pathway in ceramide metabolism and signaling. Cellular signalling 20, 1010-1018.

Kolter, T., Proia, R.L., and Sandhoff, K. (2002). Combinatorial ganglioside biosynthesis. The Journal of biological chemistry 277, 25859-25862. 
Kong, J.Y., Klassen, S.S., and Rabkin, S.W. (2005). Ceramide activates a mitochondrial p38 mitogen-activated protein kinase: a potential mechanism for loss of mitochondrial transmembrane potential and apoptosis. Molecular and cellular biochemistry 278, 39-51.

Kristal, B.S., and Brown, A.M. (1999). Apoptogenic ganglioside GD3 directly induces the mitochondrial permeability transition. The Journal of biological chemistry 274, 23169-23175.

Kroemer, G., Dallaporta, B., and Resche-Rigon, M. (1998). The mitochondrial death/life regulator in apoptosis and necrosis. Annu Rev Physiol 60, 619-642.

Kroemer, G., Galluzzi, L., and Brenner, C. (2007). Mitochondrial membrane permeabilization in cell death. Physiol Rev 87, 99-163.

Kubota, M., Kitahara, S., Shimasaki, H., and Ueta, N. (1989). Accumulation of ceramide in ischemic human brain of an acute case of cerebral occlusion. The Japanese journal of experimental medicine 59, 59-64.

Kubota, M., Narita, K., Nakagomi, T., Tamura, A., Shimasaki, H., Ueta, N., and Yoshida, S. (1996). Sphingomyelin changes in rat cerebral cortex during focal ischemia. Neurol Res 18, 337-341.

Kurinna, S.M., Tsao, C.C., Nica, A.F., Jiffar, T., and Ruvolo, P.P. (2004). Ceramide promotes apoptosis in lung cancer-derived A549 cells by a mechanism involving c-Jun NH2terminal kinase. Cancer research 64, 7852-7856.

Lahiri, S., and Futerman, A.H. (2005). LASS5 is a bona fide dihydroceramide synthase that selectively utilizes palmitoyl-CoA as acyl donor. The Journal of biological chemistry 280, 33735-33738.

Laviad, E.L., Albee, L., Pankova-Kholmyansky, I., Epstein, S., Park, H., Merrill, A.H., Jr., and Futerman, A.H. (2008). Characterization of ceramide synthase 2: tissue distribution, substrate specificity, and inhibition by sphingosine 1-phosphate. J Biol Chem 283, 5677-5684.

Lei, K., and Davis, R.J. (2003). JNK phosphorylation of Bim-related members of the Bcl2 family induces Bax-dependent apoptosis. Proceedings of the National Academy of Sciences of the United States of America 100, 2432-2437.

Levy, M., Castillo, S.S., and Goldkorn, T. (2006). nSMase2 activation and trafficking are modulated by oxidative stress to induce apoptosis. Biochemical and biophysical research communications 344, 900-905.

Li, Y., Chopp, M., Jiang, N., and Zaloga, C. (1995). In situ detection of DNA fragmentation after focal cerebral ischemia in mice. Brain Res Mol Brain Res 28, 164-168.

Lin, C.F., Chen, C.L., Chang, W.T., Jan, M.S., Hsu, L.J., Wu, R.H., Tang, M.J., Chang, W.C., and Lin, Y.S. (2004). Sequential caspase-2 and caspase- 8 activation upstream of mitochondria during ceramideand etoposide-induced apoptosis. The Journal of biological chemistry 279, 40755-40761.

Liu, J., Ginis, I., Spatz, M., and Hallenbeck, J.M. (2000). Hypoxic preconditioning protects cultured neurons against hypoxic stress via TNF-alpha and ceramide. American journal of physiology 278, C144-153. 
Llacuna, L., Mari, M., Garcia-Ruiz, C., Fernandez-Checa, J.C., and Morales, A. (2006). Critical role of acidic sphingomyelinase in murine hepatic ischemia-reperfusion injury. Hepatology (Baltimore, Md 44, 561-572.

Lopez-Montero, I., Rodriguez, N., Cribier, S., Pohl, A., Velez, M., and Devaux, P.F. (2005). Rapid transbilayer movement of ceramides in phospholipid vesicles and in human erythrocytes. The Journal of biological chemistry 280, 25811-25819.

Mandon, E.C., Ehses, I., Rother, J., van Echten, G., and Sandhoff, K. (1992). Subcellular localization and membrane topology of serine palmitoyltransferase, 3dehydrosphinganine reductase, and sphinganine $\mathrm{N}$-acyltransferase in mouse liver. The Journal of biological chemistry 267, 11144-11148.

Marchesini, N., Osta, W., Bielawski, J., Luberto, C., Obeid, L.M., and Hannun, Y.A. (2004). Role for mammalian neutral sphingomyelinase 2 in confluence-induced growth arrest of MCF7 cells. The Journal of biological chemistry 279, 25101-25111.

Merrill, A.H., Jr. (2002). De novo sphingolipid biosynthesis: a necessary, but dangerous, pathway. J Biol Chem 277, 25843-25846.

Mesicek, J., Lee, H., Feldman, T., Jiang, X., Skobeleva, A., Berdyshev, E.V., HaimovitzFriedman, A., Fuks, Z., and Kolesnick, R. (2010). Ceramide synthases 2, 5, and 6 confer distinct roles in radiation-induced apoptosis in HeLa cells. Cell Signal 22, 1300-1307.

Michel, C., and van Echten-Deckert, G. (1997). Conversion of dihydroceramide to ceramide occurs at the cytosolic face of the endoplasmic reticulum. FEBS letters 416, 153-155.

Milhas, D., Clarke, C.J., and Hannun, Y.A. (2010). Sphingomyelin metabolism at the plasma membrane: implications for bioactive sphingolipids. FEBS letters 584, 1887-1894.

Millward, T.A., Zolnierowicz, S., and Hemmings, B.A. (1999). Regulation of protein kinase cascades by protein phosphatase 2A. Trends Biochem Sci 24, 186-191.

Mimeault, M. (2002). New advances on structural and biological functions of ceramide in apoptotic/necrotic cell death and cancer. FEBS letters 530, 9-16.

Mizutani, Y., Kihara, A., and Igarashi, Y. (2005). Mammalian Lass6 and its related family members regulate synthesis of specific ceramides. The Biochemical journal 390, 263271.

Mizutani, Y., Kihara, A., and Igarashi, Y. (2006). LASS3 (longevity assurance homologue 3) is a mainly testis-specific (dihydro)ceramide synthase with relatively broad substrate specificity. Biochem J 398, 531-538.

Monette, J.S., Gomez, L.A., Moreau, R.F., Bemer, B.A., Taylor, A.W., and Hagen, T.M. (2010). Characteristics of the rat cardiac sphingolipid pool in two mitochondrial subpopulations. Biochem Biophys Res Commun 398, 272-277.

Montes, L.R., Ruiz-Arguello, M.B., Goni, F.M., and Alonso, A. (2002). Membrane restructuring via ceramide results in enhanced solute efflux. The Journal of biological chemistry 277, 11788-11794.

Morales, A., Lee, H., Goni, F.M., Kolesnick, R., and Fernandez-Checa, J.C. (2007). Sphingolipids and cell death. Apoptosis 12, 923-939.

Morell, P., and Radin, N.S. (1970). Specificity in ceramide biosynthesis from long chain bases and various fatty acyl coenzyme A's by brain microsomes. The Journal of biological chemistry $245,342-350$. 
Murriel, C.L., Churchill, E., Inagaki, K., Szweda, L.I., and Mochly-Rosen, D. (2004). Protein kinase Cdelta activation induces apoptosis in response to cardiac ischemia and reperfusion damage: a mechanism involving BAD and the mitochondria. The Journal of biological chemistry 279, 47985-47991.

Nakagawa, T., Shimizu, S., Watanabe, T., Yamaguchi, O., Otsu, K., Yamagata, H., Inohara, H., Kubo, T., and Tsujimoto, Y. (2005). Cyclophilin D-dependent mitochondrial permeability transition regulates some necrotic but not apoptotic cell death. Nature $434,652-658$.

Nakai, A., Kuroda, S., Kristian, T., and Siesjo, B.K. (1997). The immunosuppressant drug FK506 ameliorates secondary mitochondrial dysfunction following transient focal cerebral ischemia in the rat. Neurobiol Dis 4, 288-300.

Nakane, M., Kubota, M., Nakagomi, T., Tamura, A., Hisaki, H., Shimasaki, H., and Ueta, N. (2000). Lethal forebrain ischemia stimulates sphingomyelin hydrolysis and ceramide generation in the gerbil hippocampus. Neurosci Lett 296, 89-92.

Nilsson, A., and Duan, R.D. (2006). Absorption and lipoprotein transport of sphingomyelin. Journal of lipid research 47, 154-171.

Noureddine, L., Azzam, R., Nemer, G., Bielawski, J., Nasser, M., Bitar, F., and Dbaibo, G.S. (2008). Modulation of total ceramide and constituent ceramide species in the acutely and chronically hypoxic mouse heart at different ages. Prostaglandins \& other lipid mediators 86, 49-55.

Novgorodov, S.A., Chudakova, D.A., Wheeler, B.W., Bielawski, J., Kindy, M.S., Obeid, L.M., and Gudz, T.I. (2011a). Developmentally regulated ceramide synthase 6 increases mitochondrial $\mathrm{Ca} 2+$ loading capacity and promotes apoptosis. The Journal of biological chemistry 286, 4644-4658.

Novgorodov, S.A., and Gudz, T.I. (1996). Permeability transition pore of the inner mitochondrial membrane can operate in two open states with different selectivities. Journal of bioenergetics and biomembranes 28, 139-146.

Novgorodov, S.A., Gudz, T.I., and Obeid, L.M. (2008). Long-chain ceramide is a potent inhibitor of the mitochondrial permeability transition pore. The Journal of biological chemistry 283, 24707-24717.

Novgorodov, S.A., Szulc, Z.M., Luberto, C., Jones, J.A., Bielawski, J., Bielawska, A., Hannun, Y.A., and Obeid, L.M. (2005). Positively charged ceramide is a potent inducer of mitochondrial permeabilization. The Journal of biological chemistry 280, 1609616105.

Novgorodov, S.A., Wu, B.X., Gudz, T.I., Bielawski, J., Ovchinnikova, T.V., Hannun, Y.A., and Obeid, L.M. (2011b). Novel Pathway of Ceramide Production in Mitochondria: THIOESTERASE AND NEUTRAL CERAMIDASE PRODUCE CERAMIDE FROM SPHINGOSINE AND ACYL-CoA. The Journal of biological chemistry 286, 2535225362.

O'Brien, N.W., Gellings, N.M., Guo, M., Barlow, S.B., Glembotski, C.C., and Sabbadini, R.A. (2003). Factor associated with neutral sphingomyelinase activation and its role in cardiac cell death. Circulation research 92, 589-591.

Ogretmen, B., and Hannun, Y.A. (2004). Biologically active sphingolipids in cancer pathogenesis and treatment. Nat Rev Cancer 4, 604-616. 
Ohtani, R., Tomimoto, H., Kondo, T., Wakita, H., Akiguchi, I., Shibasaki, H., and Okazaki, T. (2004). Upregulation of ceramide and its regulating mechanism in a rat model of chronic cerebral ischemia. Brain Res 1023, 31-40.

Ott, M., Gogvadze, V., Orrenius, S., and Zhivotovsky, B. (2007). Mitochondria, oxidative stress and cell death. Apoptosis 12, 913-922.

Pacher, P., and Hajnoczky, G. (2001). Propagation of the apoptotic signal by mitochondrial waves. Embo J 20, 4107-4121.

Parra, V., Eisner, V., Chiong, M., Criollo, A., Moraga, F., Garcia, A., Hartel, S., Jaimovich, E., Zorzano, A., Hidalgo, C., et al. (2008). Changes in mitochondrial dynamics during ceramide-induced cardiomyocyte early apoptosis. Cardiovascular research 77, 387397.

Pastorino, J.G., Simbula, G., Yamamoto, K., Glascott, P.A., Jr., Rothman, R.J., and Farber, J.L. (1996). The cytotoxicity of tumor necrosis factor depends on induction of the mitochondrial permeability transition. The Journal of biological chemistry 271, 29792-29798.

Pastorino, J.G., Tafani, M., Rothman, R.J., Marcinkeviciute, A., Hoek, J.B., and Farber, J.L. (1999a). Functional consequences of the sustained or transient activation by Bax of the mitochondrial permeability transition pore. The Journal of biological chemistry 274, 31734-31739.

Pastorino, J.G., Tafani, M., Rothman, R.J., Marcinkeviciute, A., Hoek, J.B., Farber, J.L., and Marcineviciute, A. (1999b). Functional consequences of the sustained or transient activation by Bax of the mitochondrial permeability transition pore. The Journal of biological chemistry 274, 31734-31739.

Pchejetski, D., Kunduzova, O., Dayon, A., Calise, D., Seguelas, M.H., Leducq, N., Seif, I., Parini, A., and Cuvillier, O. (2007). Oxidative stress-dependent sphingosine kinase1 inhibition mediates monoamine oxidase A-associated cardiac cell apoptosis. Circulation research 100, 41-49.

Perry, R.J., and Ridgway, N.D. (2005). Molecular mechanisms and regulation of ceramide transport. Biochimica et biophysica acta 1734, 220-234.

Pettus, B.J., Chalfant, C.E., and Hannun, Y.A. (2002). Ceramide in apoptosis: an overview and current perspectives. Biochimica et biophysica acta 1585, 114-125.

Pettus, B.J., Kroesen, B.J., Szulc, Z.M., Bielawska, A., Bielawski, J., Hannun, Y.A., and Busman, M. (2004). Quantitative measurement of different ceramide species from crude cellular extracts by normal-phase high-performance liquid chromatography coupled to atmospheric pressure ionization mass spectrometry. Rapid Commun Mass Spectrom 18, 577-583.

Pewzner-Jung, Y., Ben-Dor, S., and Futerman, A.H. (2006). When do Lasses (longevity assurance genes) become CerS (ceramide synthases)?: Insights into the regulation of ceramide synthesis. The Journal of biological chemistry 281, 25001-25005.

Phillips, D.C., Martin, S., Doyle, B.T., and Houghton, J.A. (2007). Sphingosine-induced apoptosis in rhabdomyosarcoma cell lines is dependent on pre-mitochondrial Bax activation and post-mitochondrial caspases. Cancer research 67, 756-764.

Pinton, P., Ferrari, D., Rapizzi, E., Di Virgilio, F., Pozzan, T., and Rizzuto, R. (2001). The $\mathrm{Ca} 2+$ concentration of the endoplasmic reticulum is a key determinant of ceramide- 
induced apoptosis: significance for the molecular mechanism of Bcl-2 action. Embo J 20, 2690-2701.

Quillet-Mary, A., Jaffrezou, J.P., Mansat, V., Bordier, C., Naval, J., and Laurent, G. (1997). Implication of mitochondrial hydrogen peroxide generation in ceramide-induced apoptosis. The Journal of biological chemistry 272, 21388-21395.

Rippo, M.R., Malisan, F., Ravagnan, L., Tomassini, B., Condo, I., Costantini, P., Susin, S.A., Rufini, A., Todaro, M., Kroemer, G., et al. (2000). GD3 ganglioside directly targets mitochondria in a bcl-2-controlled fashion. Faseb J 14, 2047-2054.

Ruvolo, P.P., Deng, X., Ito, T., Carr, B.K., and May, W.S. (1999). Ceramide induces Bcl2 dephosphorylation via a mechanism involving mitochondrial PP2A. The Journal of biological chemistry 274, 20296-20300.

Scaffidi, C., Schmitz, I., Zha, J., Korsmeyer, S.J., Krammer, P.H., and Peter, M.E. (1999). Differential modulation of apoptosis sensitivity in CD95 type I and type II cells. The Journal of biological chemistry 274, 22532-22538.

Schinzel, A.C., Takeuchi, O., Huang, Z., Fisher, J.K., Zhou, Z., Rubens, J., Hetz, C., Danial, N.N., Moskowitz, M.A., and Korsmeyer, S.J. (2005). Cyclophilin D is a component of mitochondrial permeability transition and mediates neuronal cell death after focal cerebral ischemia. Proceedings of the National Academy of Sciences of the United States of America 102, 12005-12010.

Schissel, S.L., Jiang, X., Tweedie-Hardman, J., Jeong, T., Camejo, E.H., Najib, J., Rapp, J.H., Williams, K.J., and Tabas, I. (1998). Secretory sphingomyelinase, a product of the acid sphingomyelinase gene, can hydrolyze atherogenic lipoproteins at neutral $\mathrm{pH}$. Implications for atherosclerotic lesion development. The Journal of biological chemistry 273, 2738-2746.

Scorrano, L., Oakes, S.A., Opferman, J.T., Cheng, E.H., Sorcinelli, M.D., Pozzan, T., and Korsmeyer, S.J. (2003). BAX and BAK regulation of endoplasmic reticulum Ca2+: a control point for apoptosis. Science 300, 135-139.

Scorrano, L., Penzo, D., Petronilli, V., Pagano, F., and Bernardi, P. (2001). Arachidonic acid causes cell death through the mitochondrial permeability transition. Implications for tumor necrosis factor-alpha aopototic signaling. The Journal of biological chemistry 276, 12035-12040.

Scorrano, L., Petronilli, V., Di Lisa, F., and Bernardi, P. (1999). Commitment to apoptosis by GD3 ganglioside depends on opening of the mitochondrial permeability transition pore. The Journal of biological chemistry 274, 22581-22585.

Shimeno, H., Soeda, S., Sakamoto, M., Kouchi, T., Kowakame, T., and Kihara, T. (1998). Partial purification and characterization of sphingosine $\mathrm{N}$-acyltransferase (ceramide synthase) from bovine liver mitochondrion-rich fraction. Lipids 33, 601605.

Shimeno, H., Soeda, S., Yasukouchi, M., Okamura, N., and Nagamatsu, A. (1995). Fatty acylCo A: sphingosine acyltransferase in bovine brain mitochondria: its solubilization and reconstitution onto the membrane lipid liposomes. Biol Pharm Bull 18, 13351339 .

Sims, N.R., and Anderson, M.F. (2002). Mitochondrial contributions to tissue damage in stroke. Neurochem Int 40, 511-526. 
Siskind, L.J., and Colombini, M. (2000). The lipids C2- and C16-ceramide form large stable channels. Implications for apoptosis. The Journal of biological chemistry 275, 3864038644.

Siskind, L.J., Feinstein, L., Yu, T., Davis, J.S., Jones, D., Choi, J., Zuckerman, J.E., Tan, W., Hill, R.B., Hardwick, J.M., et al. (2008). Anti-apoptotic Bcl-2 Family Proteins Disassemble Ceramide Channels. J Biol Chem 283, 6622-6630.

Siskind, L.J., Kolesnick, R.N., and Colombini, M. (2002). Ceramide channels increase the permeability of the mitochondrial outer membrane to small proteins. The Journal of biological chemistry 277, 26796-26803.

Siskind, L.J., Kolesnick, R.N., and Colombini, M. (2006). Ceramide forms channels in mitochondrial outer membranes at physiologically relevant concentrations. Mitochondrion 6, 118-125.

Snook, C.F., Jones, J.A., and Hannun, Y.A. (2006). Sphingolipid-binding proteins. Biochimica et biophysica acta 1761, 927-946.

Sonnino, S., Prinetti, A., Mauri, L., Chigorno, V., and Tettamanti, G. (2006). Dynamic and structural properties of sphingolipids as driving forces for the formation of membrane domains. Chemical reviews 106, 2111-2125.

Sot, J., Aranda, F.J., Collado, M.I., Goni, F.M., and Alonso, A. (2005a). Different effects of long- and short-chain ceramides on the gel-fluid and lamellar-hexagonal transitions of phospholipids: a calorimetric, NMR, and x-ray diffraction study. Biophysical journal 88, 3368-3380.

Sot, J., Goni, F.M., and Alonso, A. (2005b). Molecular associations and surface-active properties of short- and long-N-acyl chain ceramides. Biochimica et biophysica acta $1711,12-19$.

Spassieva, S., Seo, J.G., Jiang, J.C., Bielawski, J., Alvarez-Vasquez, F., Jazwinski, S.M., Hannun, Y.A., and Obeid, L.M. (2006). Necessary role for the Lag1p motif in (dihydro)ceramide synthase activity. J Biol Chem.

Spence, M.W., Byers, D.M., Palmer, F.B., and Cook, H.W. (1989). A new Zn2+-stimulated sphingomyelinase in fetal bovine serum. The Journal of biological chemistry 264, 5358-5363.

Sridevi, P., Alexander, H., Laviad, E.L., Pewzner-Jung, Y., Hannink, M., Futerman, A.H., and Alexander, S. (2009). Ceramide synthase 1 is regulated by proteasomal mediated turnover. Biochimica et biophysica acta.

Stancevic, B., and Kolesnick, R. (2010). Ceramide-rich platforms in transmembrane signaling. FEBS letters 584, 1728-1740.

Stavrovskaya, I.G., and Kristal, B.S. (2005). The powerhouse takes control of the cell: is the mitochondrial permeability transition a viable therapeutic target against neuronal dysfunction and death? Free Radic Biol Med 38, 687-697.

Stiban, J., Caputo, L., and Colombini, M. (2008). Ceramide synthesis in the endoplasmic reticulum can permeabilize mitochondria to proapoptotic proteins. Journal of lipid research 49, 625-634.

Stoica, B.A., Movsesyan, V.A., Lea, P.M.t., and Faden, A.I. (2003). Ceramide-induced neuronal apoptosis is associated with dephosphorylation of Akt, BAD, FKHR, 
GSK-3beta, and induction of the mitochondrial-dependent intrinsic caspase pathway. Mol Cell Neurosci 22, 365-382.

Suen, D.F., Norris, K.L., and Youle, R.J. (2008). Mitochondrial dynamics and apoptosis. Genes \& development 22, 1577-1590.

Sullards, M.C. (2000). Analysis of sphingomyelin, glucosylceramide, ceramide, sphingosine, and sphingosine 1-phosphate by tandem mass spectrometry. Methods in enzymology 312, 32-45.

Sumitomo, M., Ohba, M., Asakuma, J., Asano, T., Kuroki, T., and Hayakawa, M. (2002). Protein kinase Cdelta amplifies ceramide formation via mitochondrial signaling in prostate cancer cells. J Clin Invest 109, 827-836.

Szabadkai, G., and Duchen, M.R. (2008). Mitochondria: the hub of cellular Ca2+ signaling. Physiology (Bethesda, Md 23, 84-94.

Szalai, G., Krishnamurthy, R., and Hajnoczky, G. (1999). Apoptosis driven by IP(3)-linked mitochondrial calcium signals. Embo J 18, 6349-6361.

Tabas, I. (1999). Secretory sphingomyelinase. Chemistry and physics of lipids 102, 123-130.

Taha, T.A., Mullen, T.D., and Obeid, L.M. (2006). A house divided: Ceramide, sphingosine, and sphingosine-1-phosphate in programmed cell death. Biochimica et biophysica acta 1758, 2027-2036.

Takahashi, K., Ginis, I., Nishioka, R., Klimanis, D., Barone, F.C., White, R.F., Chen, Y., and Hallenbeck, J.M. (2004). Glucosylceramide synthase activity and ceramide levels are modulated during cerebral ischemia after ischemic preconditioning. J Cereb Blood Flow Metab 24, 623-627.

Tani, M., Igarashi, Y., and Ito, M. (2005). Involvement of neutral ceramidase in ceramide metabolism at the plasma membrane and in extracellular milieu. J Biol Chem 280, 36592-36600.

Tani, M., Ito, M., and Igarashi, Y. (2007). Ceramide/sphingosine/sphingosine 1-phosphate metabolism on the cell surface and in the extracellular space. Cellular signalling 19, 229-237.

Therade-Matharan, S., Laemmel, E., Carpentier, S., Obata, Y., Levade, T., Duranteau, J., and Vicaut, E. (2005). Reactive oxygen species production by mitochondria in endothelial cells exposed to reoxygenation after hypoxia and glucose depletion is mediated by ceramide. Am J Physiol Regul Integr Comp Physiol 289, R1756-1762.

Tomiuk, S., Zumbansen, M., and Stoffel, W. (2000). Characterization and subcellular localization of murine and human magnesium-dependent neutral sphingomyelinase. The Journal of biological chemistry 275, 5710-5717.

Tserng, K.Y., and Griffin, R. (2003). Quantitation and molecular species determination of diacylglycerols, phosphatidylcholines, ceramides, and sphingomyelins with gas chromatography. Anal Biochem 323, 84-93.

Ullman, M.D., and Radin, N.S. (1972). Enzymatic formation of hydroxy ceramides and comparison with enzymes forming nonhydroxy ceramides. Arch Biochem Biophys 152, 767-777.

Vaena de Avalos, S., Okamoto, Y., and Hannun, Y.A. (2004). Activation and localization of inositol phosphosphingolipid phospholipase C, Isc1p, to the mitochondria during growth of Saccharomyces cerevisiae. J Biol Chem 279, 11537-11545. 
Vander Heiden, M.G., Chandel, N.S., Williamson, E.K., Schumacker, P.T., and Thompson, C.B. (1997). Bcl-xL regulates the membrane potential and volume homeostasis of mitochondria. Cell 91, 627-637.

Venkataraman, K., and Futerman, A.H. (2002). Do longevity assurance genes containing Hox domains regulate cell development via ceramide synthesis? FEBS letters 528, 34.

Votyakova, T.V., and Reynolds, I.J. (2001). DeltaPsi(m)-Dependent and -independent production of reactive oxygen species by rat brain mitochondria. Journal of neurochemistry 79, 266-277.

Weston, C.R., and Davis, R.J. (2007). The JNK signal transduction pathway. Current opinion in cell biology 19, 142-149.

Won, J.S., and Singh, I. (2006). Sphingolipid signaling and redox regulation. Free radical biology \& medicine 40, 1875-1888.

Wooten-Blanks, L.G., Song, P., Senkal, C.E., and Ogretmen, B. (2007). Mechanisms of ceramide-mediated repression of the human telomerase reverse transcriptase promoter via deacetylation of Sp3 by histone deacetylase 1. Faseb J 21, 3386-3397.

Wu, B.X., Rajagopalan, V., Roddy, P.L., Clarke, C.J., and Hannun, Y.A. (2010). Identification and characterization of murine mitochondria-associated neutral sphingomyelinase (MA-nSMase), the mammalian sphingomyelin phosphodiesterase 5. The Journal of biological chemistry 285, 17993-18002.

Xin, M., and Deng, X. (2006). Protein phosphatase 2A enhances the proapoptotic function of Bax through dephosphorylation. The Journal of biological chemistry 281, 1885918867.

Xu, X., Bittman, R., Duportail, G., Heissler, D., Vilcheze, C., and London, E. (2001). Effect of the structure of natural sterols and sphingolipids on the formation of ordered sphingolipid/sterol domains (rafts). Comparison of cholesterol to plant, fungal, and disease-associated sterols and comparison of sphingomyelin, cerebrosides, and ceramide. The Journal of biological chemistry 276, 33540-33546.

Yabu, T., Shimuzu, A., and Yamashita, M. (2009). A novel mitochondrial sphingomyelinase in zebrafish cells. J Biol Chem 284, 20349-20363.

Yu, J., Novgorodov, S.A., Chudakova, D., Zhu, H., Bielawska, A., Bielawski, J., Obeid, L.M., Kindy, M.S., and Gudz, T.I. (2007). JNK3 signaling pathway activates ceramide synthase leading to mitochondrial dysfunction. J Biol Chem 282, 25940-25949.

Yu, Z.F., Nikolova-Karakashian, M., Zhou, D., Cheng, G., Schuchman, E.H., and Mattson, M.P. (2000). Pivotal role for acidic sphingomyelinase in cerebral ischemia-induced ceramide and cytokine production, and neuronal apoptosis. J Mol Neurosci 15, 8597.

Yuan, H., Williams, S.D., Adachi, S., Oltersdorf, T., and Gottlieb, R.A. (2003). Cytochrome c dissociation and release from mitochondria by truncated Bid and ceramide. Mitochondrion 2, 237-244.

Yuan H, W.S., Adachi S, Oltersdorf T, Gottlieb RA (2003). Cytochrome c dissociation and release from mitochondria by trancated Bid and ceramide. Mitochondrion 2, 237244 . 
Zager, R.A., Conrad, S., Lochhead, K., Sweeney, E.A., Igarashi, Y., and Burkhart, K.M. (1998). Altered sphingomyelinase and ceramide expression in the setting of ischemic and nephrotoxic acute renal failure. Kidney international 53, 573-582.

Zager, R.A., Iwata, M., Conrad, D.S., Burkhart, K.M., and Igarashi, Y. (1997). Altered ceramide and sphingosine expression during the induction phase of ischemic acute renal failure. Kidney international 52, 60-70.

Zamzami, N., Marchetti, P., Castedo, M., Decaudin, D., Macho, A., Hirsch, T., Susin, S.A., Petit, P.X., Mignotte, B., and Kroemer, G. (1995). Sequential reduction of mitochondrial transmembrane potential and generation of reactive oxygen species in early programmed cell death. J Exp Med 182, 367-377.

Zeidan, Y.H., Wu, B.X., Jenkins, R.W., Obeid, L.M., and Hannun, Y.A. (2008). A novel role for protein kinase Cdelta-mediated phosphorylation of acid sphingomyelinase in UV light-induced mitochondrial injury. Faseb J 22, 183-193.

Zhang, D.X., Fryer, R.M., Hsu, A.K., Zou, A.P., Gross, G.J., Campbell, W.B., and Li, P.L. (2001). Production and metabolism of ceramide in normal and ischemic-reperfused myocardium of rats. Basic research in cardiology 96, 267-274.

Zhang, J., Alter, N., Reed, J.C., Borner, C., Obeid, L.M., and Hannun, Y.A. (1996). Bcl-2 interrupts the ceramide-mediated pathway of cell death. Proceedings of the National Academy of Sciences of the United States of America 93, 5325-5328.

Zhang, X., Li, B., Zhang, Y., and Liu, J. (2008). Ceramide induces release of mitochondrial proapoptotic proteins in caspase-dependent and -independent manner in HT-29 cells. Science in China 51, 66-71.

Zundel, W., Swiersz, L.M., and Giaccia, A. (2000). Caveolin 1-mediated regulation of receptor tyrosine kinase-associated phosphatidylinositol 3-kinase activity by ceramide. Molecular and cellular biology 20, 1507-1514. 


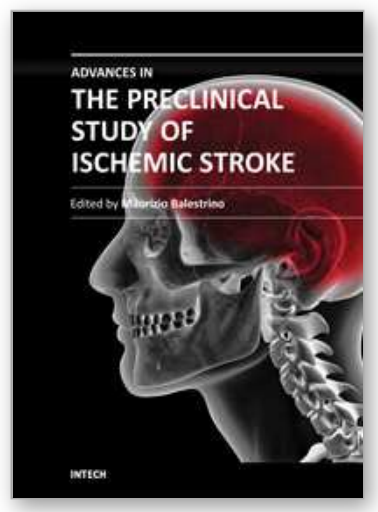

\author{
Advances in the Preclinical Study of Ischemic Stroke \\ Edited by Dr. Maurizio Balestrino
}

ISBN 978-953-51-0290-8

Hard cover, 530 pages

Publisher InTech

Published online 16, March, 2012

Published in print edition March, 2012

This book reports innovations in the preclinical study of stroke, including - novel tools and findings in animal models of stroke, - novel biochemical mechanisms through which ischemic damage may be both generated and limited, - novel pathways to neuroprotection. Although hypothermia has been so far the sole "neuroprotection" treatment that has survived the translation from preclinical to clinical studies, progress in both preclinical studies and in the design of clinical trials will hopefully provide more and better treatments for ischemic stroke. This book aims at providing the preclinical scientist with innovative knowledge and tools to investigate novel mechanisms of, and treatments for, ischemic brain damage.

\title{
How to reference
}

In order to correctly reference this scholarly work, feel free to copy and paste the following:

Tatyana I. Gudz and Sergei A. Novgorodov (2012). Mitochondrial Ceramide in Stroke, Advances in the Preclinical Study of Ischemic Stroke, Dr. Maurizio Balestrino (Ed.), ISBN: 978-953-51-0290-8, InTech, Available from: http://www.intechopen.com/books/advances-in-the-preclinical-study-of-ischemicstroke/mitochondrial-ceramide-in-stroke

\section{INTECH}

open science | open minds

\section{InTech Europe}

University Campus STeP Ri

Slavka Krautzeka 83/A

51000 Rijeka, Croatia

Phone: +385 (51) 770447

Fax: +385 (51) 686166

www.intechopen.com

\section{InTech China}

Unit 405, Office Block, Hotel Equatorial Shanghai

No.65, Yan An Road (West), Shanghai, 200040, China

中国上海市延安西路65号上海国际贵都大饭店办公楼 405 单元

Phone: +86-21-62489820

Fax: +86-21-62489821 
(C) 2012 The Author(s). Licensee IntechOpen. This is an open access article distributed under the terms of the Creative Commons Attribution 3.0 License, which permits unrestricted use, distribution, and reproduction in any medium, provided the original work is properly cited. 